\title{
Innovative Signal Processing for Johnson Noise Thermometry
}

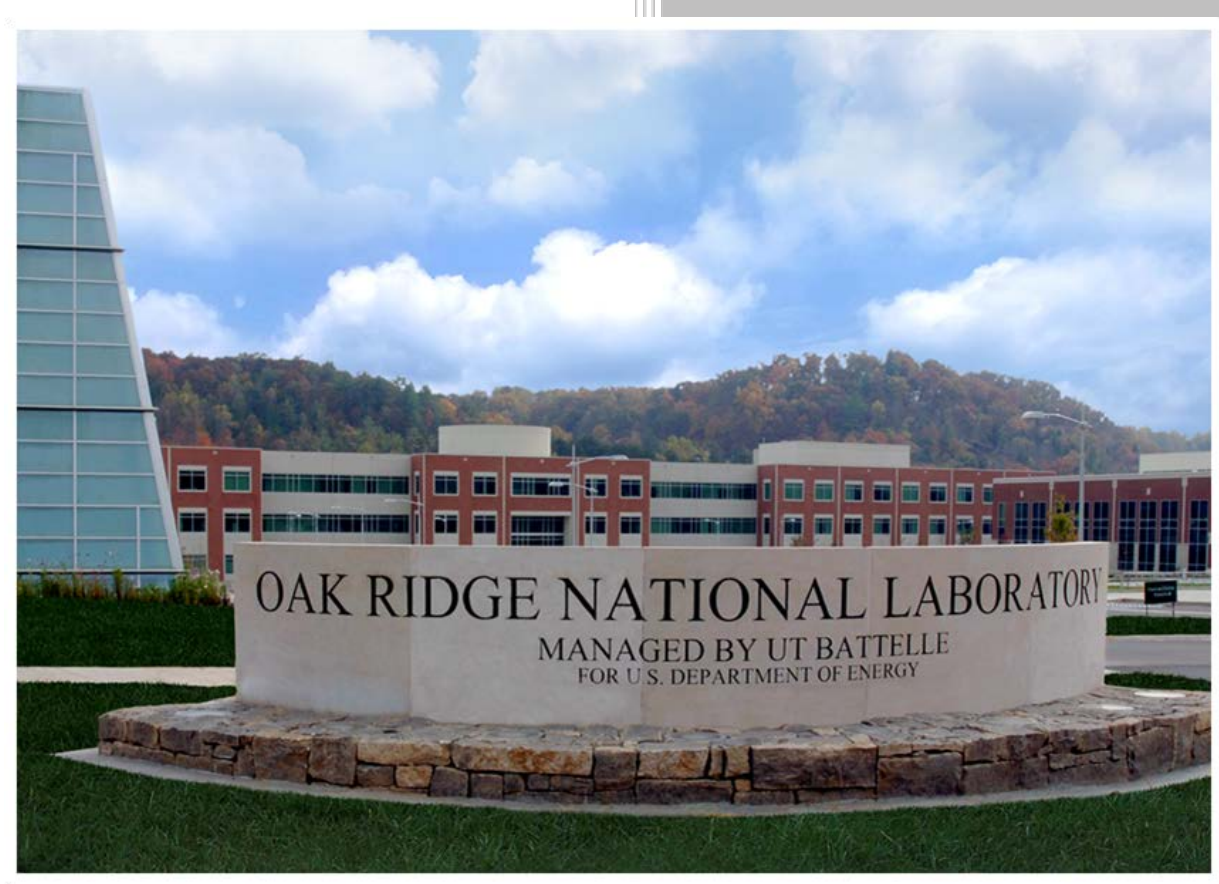

Approved for public release. Distribution is unlimited.

N. Dianne Bull Ezell Charles L. Britton Jr. Michael Roberts

July 2016 


\title{
DOCUMENT AVAILABILITY
}

Reports produced after January 1, 1996, are generally available free via US Department of Energy (DOE) SciTech Connect.

\section{Website http://www.osti.gov/scitech/}

Reports produced before January 1, 1996, may be purchased by members of the public from the following source:

\author{
National Technical Information Service \\ 5285 Port Royal Road \\ Springfield, VA 22161 \\ Telephone 703-605-6000 (1-800-553-6847) \\ TDD 703-487-4639 \\ Fax 703-605-6900 \\ E-mail info@ntis.gov \\ Website http://www.ntis.gov/help/ordermethods.aspx
}

Reports are available to DOE employees, DOE contractors, Energy Technology Data Exchange representatives, and International Nuclear Information System representatives from the following source:

Office of Scientific and Technical Information

PO Box 62

Oak Ridge, TN 37831

Telephone 865-576-8401

Fax 865-576-5728

E-mail reports@osti.gov

Website http://www.osti.gov/contact.html

This report was prepared as an account of work sponsored by an agency of the United States Government. Neither the United States Government nor any agency thereof, nor any of their employees, makes any warranty, express or implied, or assumes any legal liability or responsibility for the accuracy, completeness, or usefulness of any information, apparatus, product, or process disclosed, or represents that its use would not infringe privately owned rights. Reference herein to any specific commercial product, process, or service by trade name, trademark, manufacturer, or otherwise, does not necessarily constitute or imply its endorsement, recommendation, or favoring by the United States Government or any agency thereof. The views and opinions of authors expressed herein do not necessarily state or reflect those of the United States Government or any agency thereof. 
Electrical \& Electronics Systems Research

\title{
INNOVATIVE SIGNAL PROCESSING FOR JOHNSON NOISE THERMOMETRY
}

\author{
N. Dianne Bull Ezell \\ Charles L. Britton Jr. \\ Michael Roberts
}

Date Published: July 2016

Prepared by

OAK RIDGE NATIONAL LABORATORY

Oak Ridge, TN 37831-6283

managed by

UT-BATTELLE, LLC

for the

US DEPARTMENT OF ENERGY

under contract DE-AC05-00OR22725 



\section{CONTENTS}

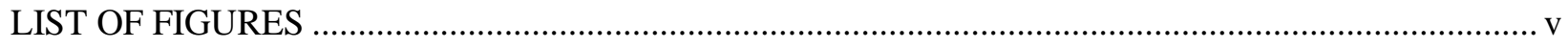

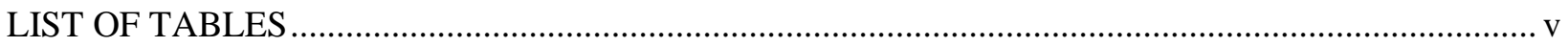

1. RATIONALE FOR DEVELOPING NEW ELECTROMAGNETIC INTERFERENCE REMOVAL TECHNIQUES AND TESTING ..........................................................

2. SOURCES OF ELECTROMAGNETIC INTERFERENCE AND THEIR IMPACT ...................... 1

3. ELECTROMAGNETIC INTERFERENCE TESTING ENVIRONMENT .....................................2

4. ELECTROMAGNETIC INTERFERENCE SPECTRAL RESULTS ...........................................6

5. CONFIGURATION OF THE SYSTEM FOR SUBTRACTION .............................................. 11

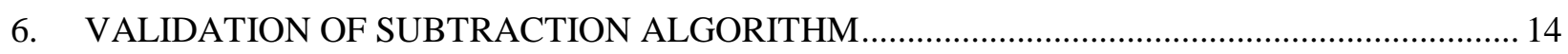

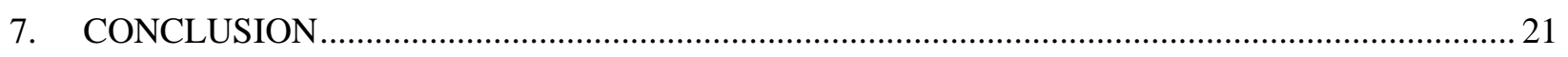

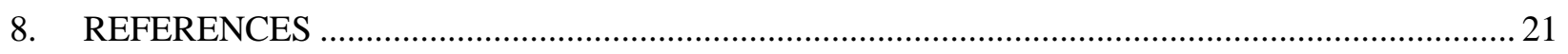





\section{LIST OF FIGURES}

1. Measurement layout at Sandia National Laboratories.......................................................... 3

2. Brayton loop resistance temperature detector locations. ......................................................... 4

3. Brayton loop Johnson noise thermometry front-end electronics. ............................................... 5

4. Baseline measurement data at each test location. ................................................................... 7

5. Measurement data with all subsystems (except heaters) on at two locations. ............................... 8

6. Measurement data with all subsystems on, heaters on, TAC on at each location........................... 9

7. Measurement data with all subsystems on, heaters on, TAC on; then system turned off

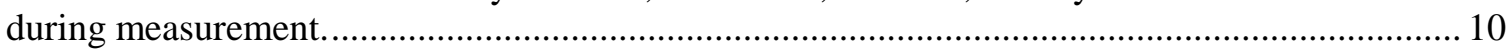

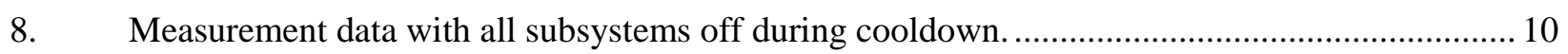

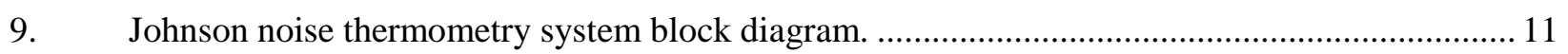

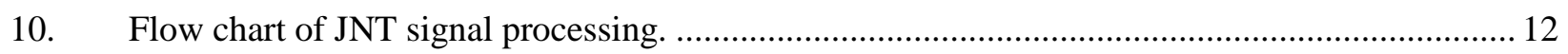

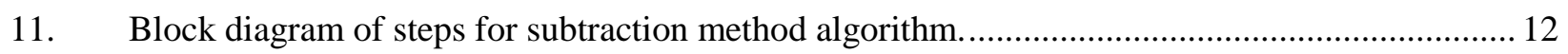

12. Measurement results from ambient EMI environment. .......................................................... 15

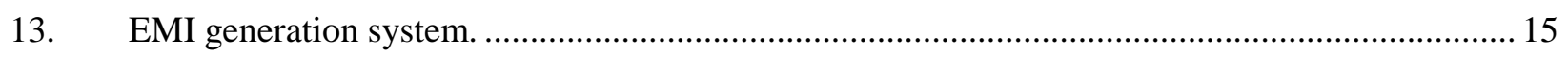

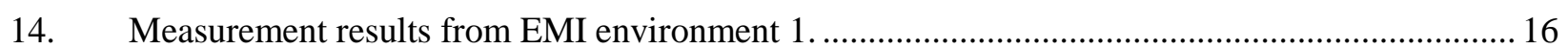

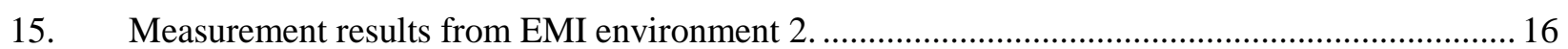

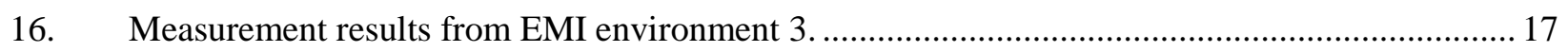

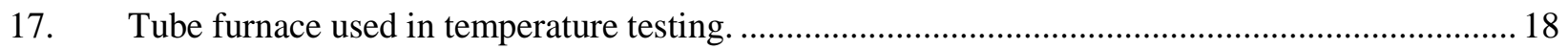

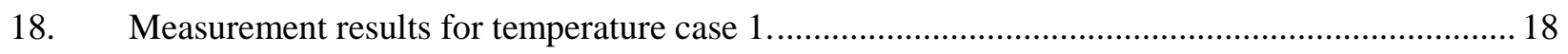

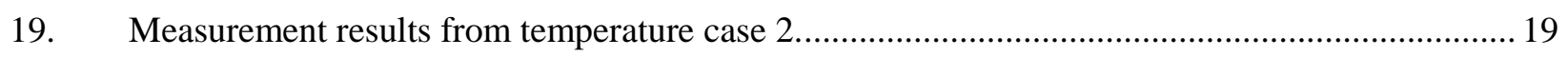

20. Measurement results from temperature case 3......................................................................... 20

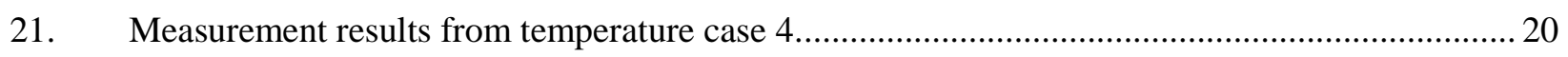

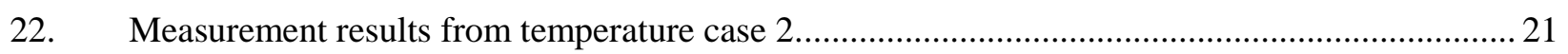

\section{LIST OF TABLES}

1. Activity log of start-up and shutdown during testing ............................................................... 5

2. EMI environments generated for validation of subtraction method ........................................... 15

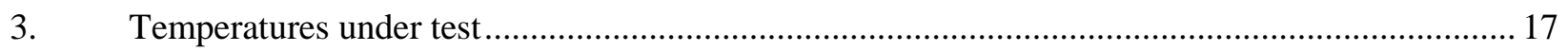

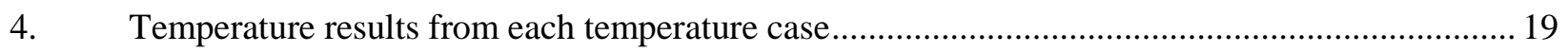





\begin{abstract}
This report summarizes the derivation of a newly developed algorithm that subtracts electromagnetic interference (EMI). EMI performance is very important to Johnson noise thermometry measurements because any interference, in the form of pickup, from external signal sources such as fluorescent lighting ballasts, motors, etc. can skew the measurement. As part of this project, two methods for removing EMI were developed and tested at various locations: rejection and subtraction. This report summarizes testing performed at different facilities outside Oak Ridge National Laboratory using the rejection EMI removal technique. The derivation of the rejection EMI removal technique was reviewed in previous milestone reports and therefore will not be covered in this report.
\end{abstract}

\title{
1. RATIONALE FOR DEVELOPING NEW ELECTROMAGNETIC INTERFERENCE REMOVAL TECHNIQUES AND TESTING
}

There were several reasons for developing a new electromagnetic interference (EMI) removal technique.

A. Linearize Process-The rejection technique is a non-linear EMI removal technique and therefore much more difficult to derive and implement. Because of the level of difficulty and unreliability, a second linear method was developed.

B. Difficult EMI environments - It became obvious, through testing at different facilities, that numerous EMI cases are not removed correctly using the rejection technique, motivating the development of a new method to handle these environments.

C. Testing at Sandia - Testing at a facility similar to the final application site allows for performance verification of the system hardware and signal processing. Sandia National Laboratories (Sandia) is the off-site location where measurements with the Johnson noise thermometry (JNT) system took place. The testing at this facility used the EMI rejection technique.

\section{SOURCES OF ELECTROMAGNETIC INTERFERENCE AND THEIR IMPACT}

EMI has a great impact on JNT measurements. Various sources, such as power lines, lights, computer power supplies, cathode-ray tubes, cellphones, motors and pumps, and data lines (e.g., the Ethernet) emit EMI [1], which can prevent accurate temperature measurement. The sources of EMI studied for this project were categorized as either transient or periodic. Transient EMI is a signal that begins, persists for some time, and then stops. Periodic EMI is a signal that is always present and repeats a pattern indefinitely. Transient EMI is a substantial deviation in the acquired signal from the expected noise voltage of the sensor. Because the sensor noise voltage has a Gaussian distribution within a known limit and a mean value equal to zero, any variations twice the standard deviation of the mean value are transient EMI. The rejection method and subtraction method use a windowing technique to detect the transient EMI. The sensor noise acquired is in blocks of data that make up of 16 "sub-blocks" of data. Each sub-block of data is evaluated with the windowing process, and if transient EMI is present, the subblock is replaced with the mean value.

Removing periodic EMI requires a different technique from that for transient EMI. In the rejection method, a "despiking” algorithm detects and rejects periodic EMI spikes. This algorithm is nonlinear and time-dependent. It also can have leakage problems [2]. For these reasons, a second method, the subtraction method, was developed. The subtraction method acquires a frequency response of the EMI 
environment through an antenna signal. Removal of periodic EMI using the subtraction method is discussed later in this document.

\section{ELECTROMAGNETIC INTERFERENCE TESTING ENVIRONMENT}

Laboratory testing at Oak Ridge National Laboratory (ORNL) has been discussed in previous documents [1]-[5]. This laboratory testing is a good proof of concept, but these environments are relatively clean of EMI. To further test the abilities of the EMI removal techniques developed as part of this project, testing was moved to two off-site locations. The first of these test locations was Sandia in Albuquerque, New Mexico. Several resistance temperature detectors (RTDs) were strategically placed at different locations on a Brayton cycle. Brayton cycle technology is a highly efficient thermal-to-electrical power conversion system [6]. The Brayton cycle is an ideal test environment because it is relatively similar to the final application for the JNT system. The locations where the RTDs were placed were selected to allow different conditions to be tested (Figure 1). Location 1 (L1) is between the gas cooler and compressor side of the turbo-alternator compressor (TAC). The expected highest temperatures at this location range from 366 to $394 \mathrm{~K}$. The RTD (Probe3) is isolated, meaning that electrically the RTD is not grounded to the system. Cable 4 is used for this measurement and is $15 \mathrm{ft}$. long. Location 2 (L2) is at the input of a high temperature heat exchanger. The expected highest temperature at this location is $644 \mathrm{~K}$. The RTD (Probe1) is also isolated. Cable 1 is used for this measurement and is $20 \mathrm{ft}$. long. Location 3 (L3) is at the junction between the output of the heaters and the input of the turbines (Figure 2). The highest temperature expected at this location is $644 \mathrm{~K}$. The RTD (Probe4) is shielded and grounded. Cable 6 is used for this measurement and is $15 \mathrm{ft}$. long. Location 4 (L4) is at the input of the compressor to the TAC (Figure 1). The highest temperature expected at this location is 366-394 K. The RTD (Probe2) is shielded and grounded. Cable 2 is used for this measurement and is $15 \mathrm{ft}$. long. Pictures of the RTDs installed on the Brayton loop are presented in Figure 2. The RTDs are highlighted in each location picture. The cable and probe combinations were calibrated before arriving at Sandia to lower parasitic contribution and allow for the best measurement. Some of the EMI sources of concern on the Brayton loop are the high voltage boxes located along the sidewall of the lab, the high voltage heater elements, and the turbine itself. Initially a baseline measurement acquired the ambient EMI. The light ballasts contributed no EMI. A dummy load (100 $\Omega$ calibration resistor) was also tested to verify validity of the measurements. This practice has been used at all testing locations since the beginning of this project. 


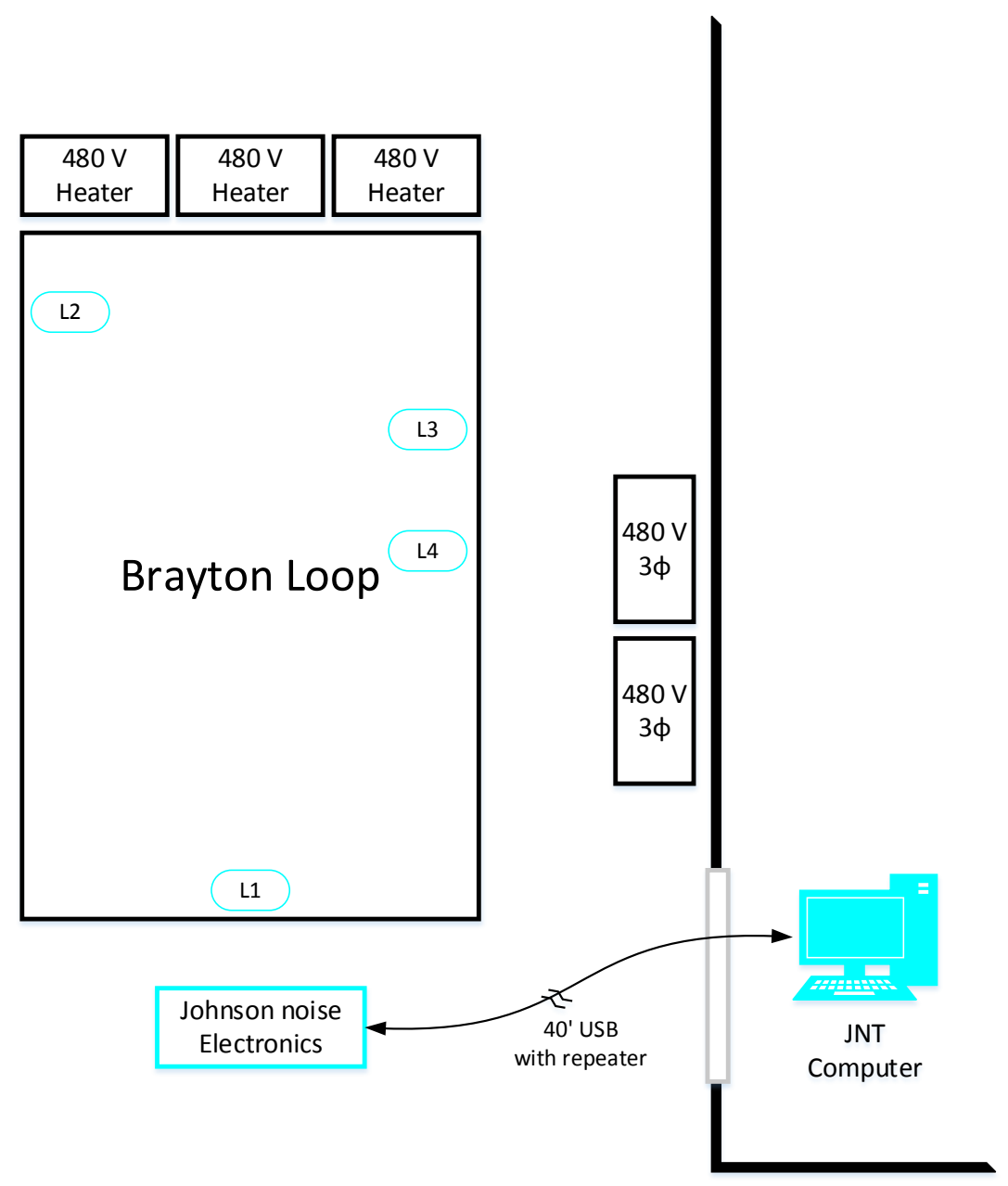

Figure 1. Measurement layout at Sandia National Laboratories. 


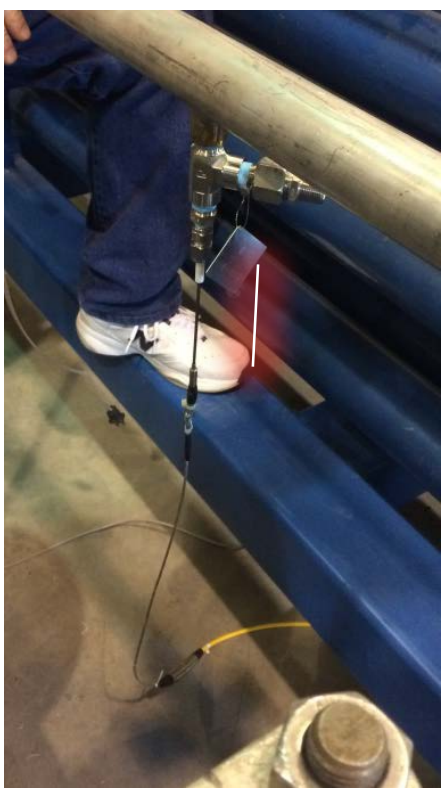

Location 1: L1

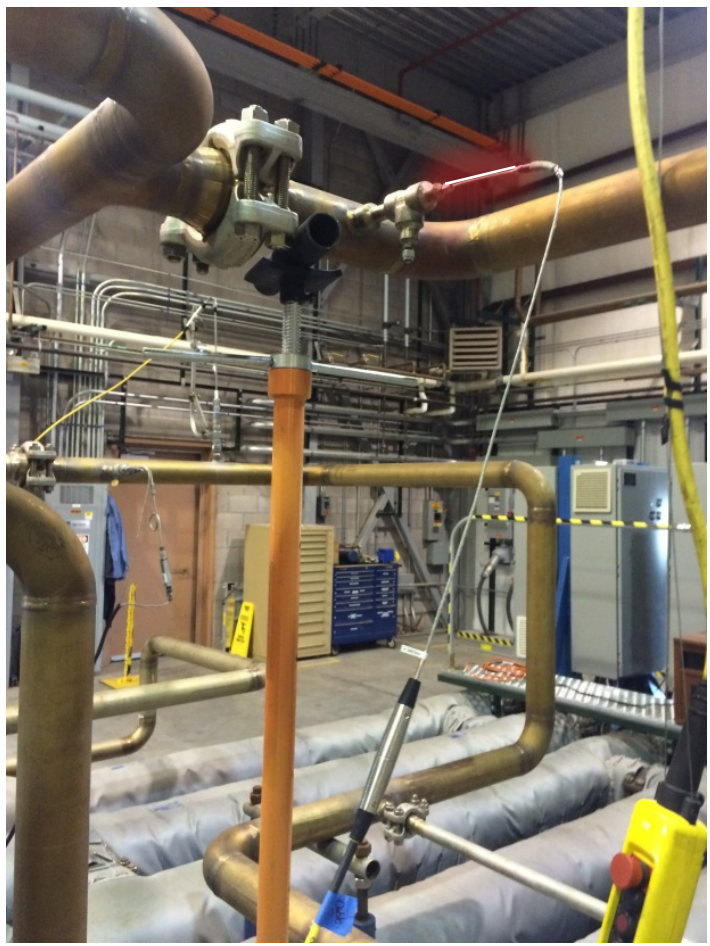

Location 3: L3

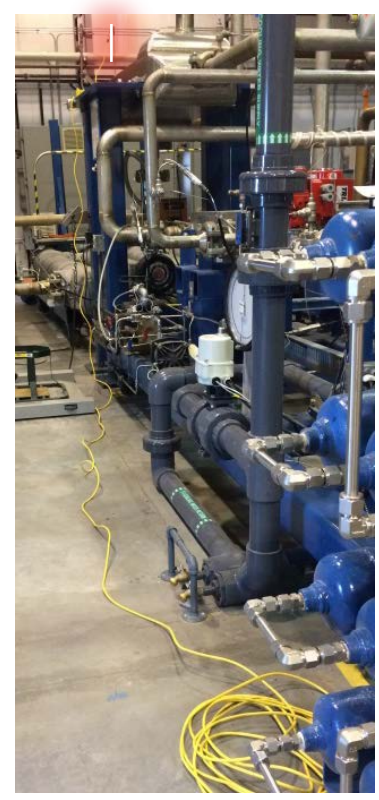

Location 2: L2

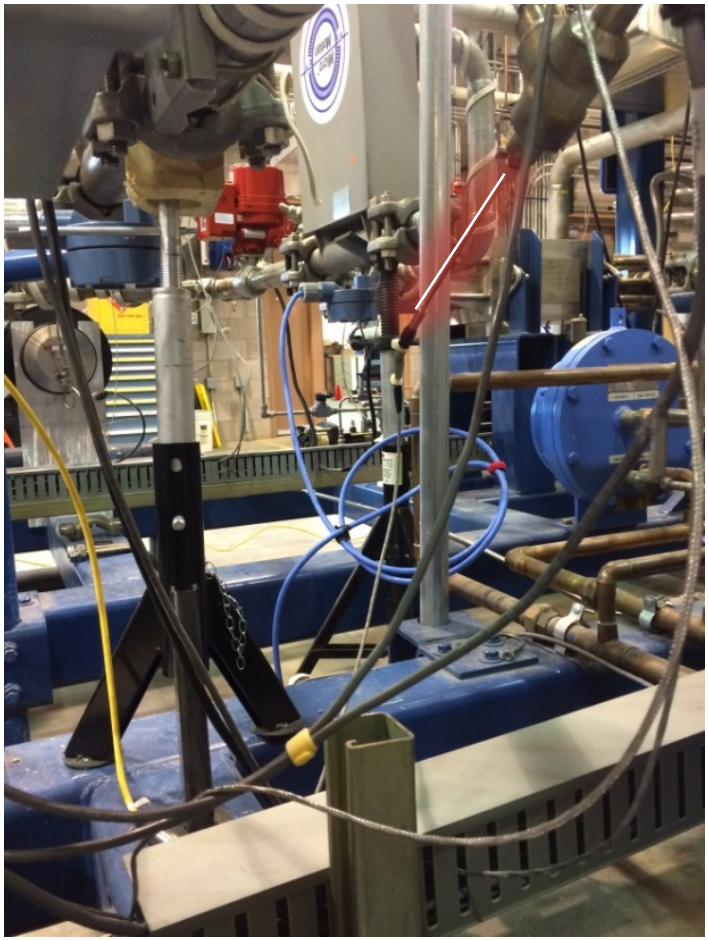

Location 4: L4

Figure 2. Brayton loop resistance temperature detector locations. 
The front-end electronics box is placed on a card just outside of the Brayton loop (Figure 3). This is a low temperature, low power location allowing access to each cable configuration during start-up and shutdown of the cycle. A log of the testing performed at the test facility was recorded for the duration of the Brayton loop start-up and shutdown. The location with RTD and cable, the start-up and shutdown process, and the EMI detected by the system are recorded in the log (Table 1).

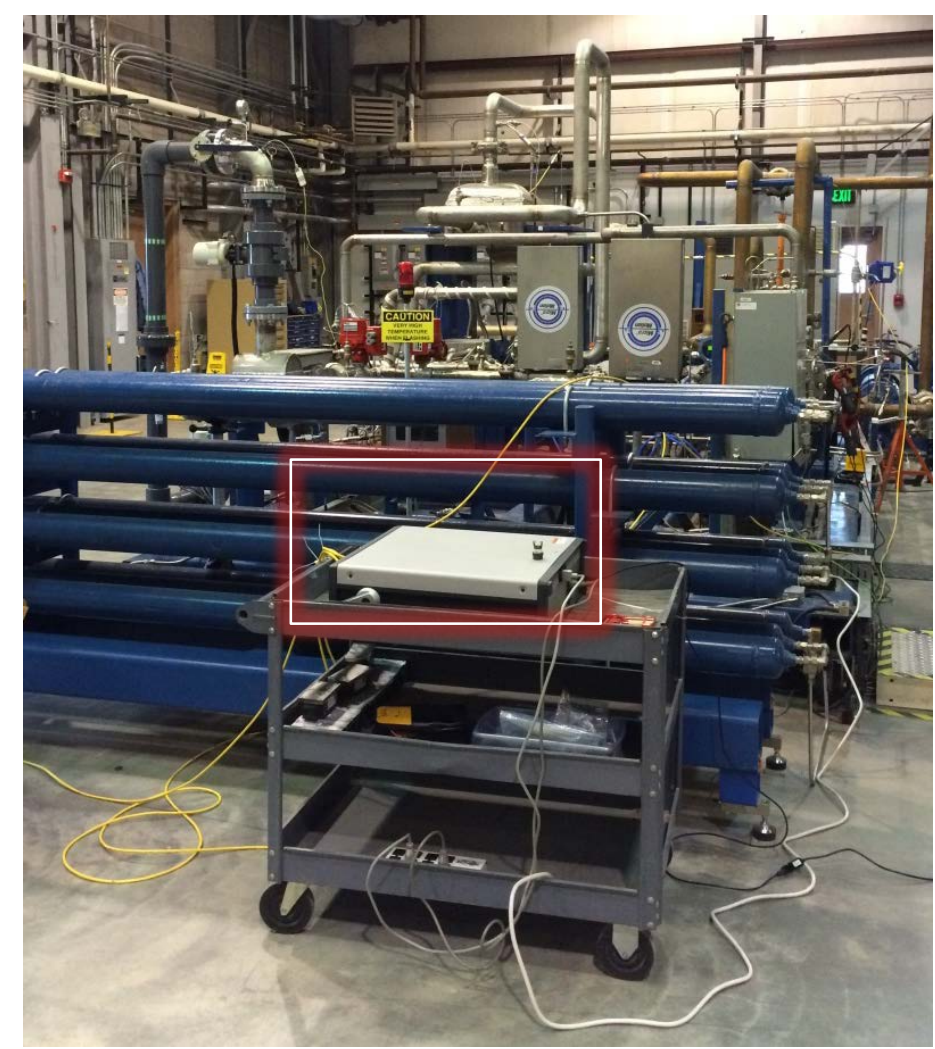

Figure 3. Brayton loop Johnson noise thermometry front-end electronics.

Table 1. Activity log of start-up and shutdown during testing

7:52 AM Probe2, Cable2 @ L4:-power started turning on but TAC off

8:00 AM Cooler pump turned on, then fans turned on

Spikes on one of the two channels begin to appear at $2 \mathrm{kHz}$, spikes on Resistor power spectral density with pilot tone on (PTRPSD) but not on Resistor power spectral density with pilot tone off (NPTRPSD)

8:08 AM $40 \mathrm{hp}$ motor turned on

Notes: $\quad 2 \mathrm{kHz}$ spikes grow on red channel and start to appear on white channel but not showing up on the Cross power spectral density (CPSD) between channel 1 and channel 2 (G12)

8:14 AM All subsystems on except heaters

Notes: $\quad$ As spikes grow on both channels, some spikes begin to appear on NPTRPSD

\begin{tabular}{ll}
\hline & \multicolumn{2}{c}{ Test STOP } \\
\hline 8:18 AM & Dummy load:-no spikes in PTRPSD \\
\hline & \multicolumn{1}{c}{ Test STOP } \\
\hline 8:20 AM & Cable6, Probe4 @ L3: \\
8:23 AM & HydroPAC turned on (switching) \\
8:29 AM & Turbines (TAC) turned on 25,000 RPM \\
& Lots of large spikes-7 V \\
8:31 AM & Heaters turned on
\end{tabular}


Table 1. (continued)

\begin{tabular}{|c|c|}
\hline \multicolumn{2}{|r|}{ Test STOP } \\
\hline 8:36 AM & Cable4, Probe3 @ L1:-all subsystems on, TAC on, heaters on 126F @ 804 lb mass/sec \\
\hline Notes: & $\begin{array}{l}\text { - Lots of noise } \\
\text { - Absolute values of noise not railing system, but the amount is the problem } \\
\text { - System staying linear }\end{array}$ \\
\hline 8:45 AM & $182.1^{\circ} \mathrm{F}, 843.49 \mathrm{lb}$ mass $/ \mathrm{sec}$ \\
\hline 9:11 AM & RPM increased by 2000—-total $=27,000$ RPM \\
\hline 9:14 AM & RPM increased by 2000—-total $=29,000$ RPM \\
\hline 9:17 AM & RPM increased by 2000—total $=31,000$ RPM \\
\hline 9:18 AM & RPM increased by 2000—-total $=32,000$ RPM \\
\hline Notes: & $\begin{array}{l}\text { - A few blocks were rejected } \\
\text { - Correlation not great } \\
\text { - Lots of spikes but linear and not saturating } \\
\text { - G12 waveform shape ugly } \\
\text { - Hard to see PT on the raw data: V1, V2 }\end{array}$ \\
\hline 9:21 AM & $\begin{array}{l}34,000 \text { RPM } \\
\text { Increase in number of rejected blocks per cycle but data still usable }\end{array}$ \\
\hline 9:23 AM & 36,000 RPM SATURATED! \\
\hline \multicolumn{2}{|r|}{ Test Stop } \\
\hline 9:27 AM & Dummy load:- good data \\
\hline 9:30 AM & $37,000 \mathrm{RPM}$ \\
\hline 9:33 AM & 38,000 RPM \\
\hline \multicolumn{2}{|r|}{ Test Stop } \\
\hline 9:27 AM & Cable1, Probe1 @ L2: all systems on, TAC on, Heaters on \\
\hline 9:38 AM & $\begin{array}{l}40,000 \text { RPM } \\
\text { G12 shape is better but still not good } \\
\text { More spikes on RPSD }\end{array}$ \\
\hline 12:40 PM & Brayton cycle loop shutdown—failure \\
\hline 12:45 PM & Restart Cable1, Probe1@ @2 as system cools down \\
\hline
\end{tabular}

\section{ELECTROMAGNETIC INTERFERENCE SPECTRAL RESULTS}

The EMI spectral results are a summary of the testing at Sandia. The baseline results, shown in Figure 4, correlate to the measurements with all system off. The measurement results for G1 [white-power spectral density (PSD) of channel 1], G2 (red-PSD of channel 1), and G12 [green-cross power spectral density (CPSD) between channels 1 and 2] are the expected shape and magnitude with little injected EMI. The only EMI spike is around $45 \mathrm{kHz}$ due to the internal signal generator. The temperature results from these measurements are not recorded but are monitored and hold at room temperature for all locations. After completing baseline testing, all subsystems are turned on except the heaters (Figure 5).

Generally the data sets show the expected white noise from the differential channels as the smooth baseline of each of the curves [1]. Looking at the measurement data, at location L4, a $2 \mathrm{kHz}$ harmonic due to EMI from the subsystems is evident. The EMI is slowly rejected over the measurement. A measurement is also acquired at the dummy load, and while the baseline is noisy, the spikes do not appear. The noisy signal is likely due to a short run time and is not broadband EMI noise. 


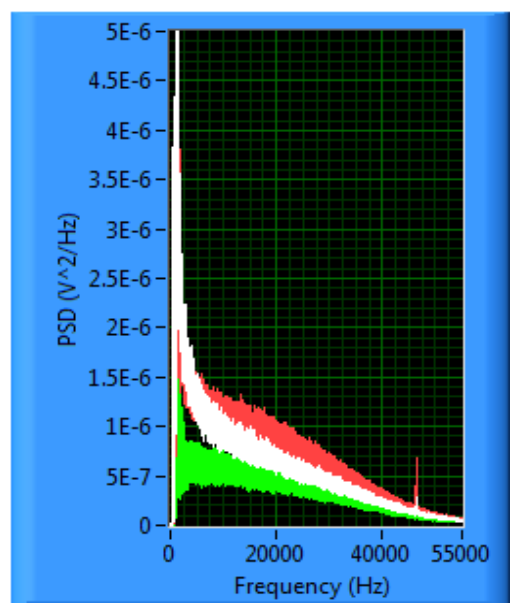

A: Load: (L1) Cable 4, RTD 3

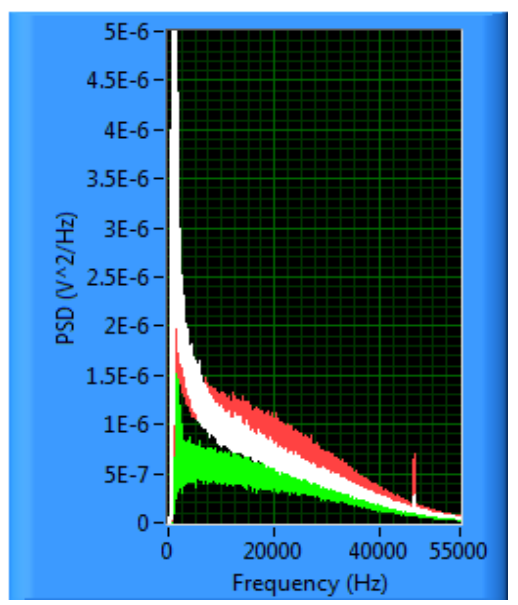

C: Load: (L3) Cable 6, RTD 4

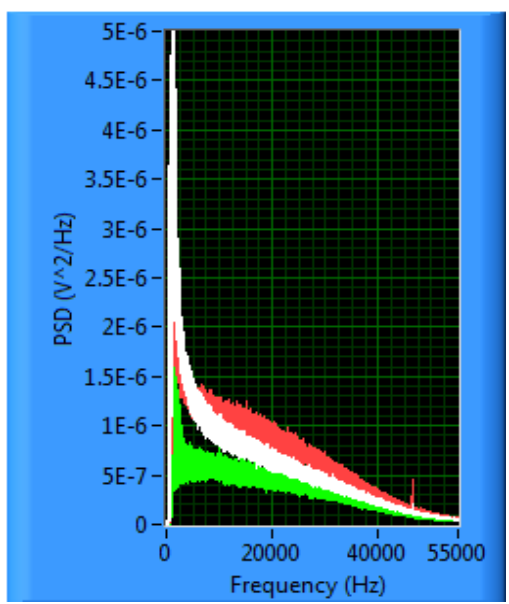

B: Load: (L2) Cable 1, RTD 1

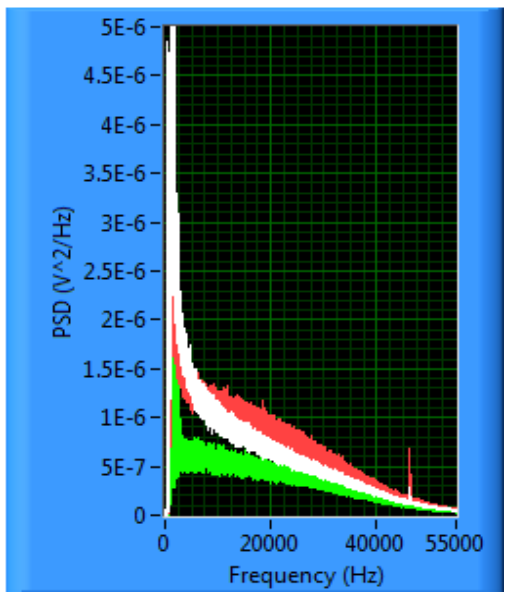

D: Load: (L4) Cable 2, RTD 2

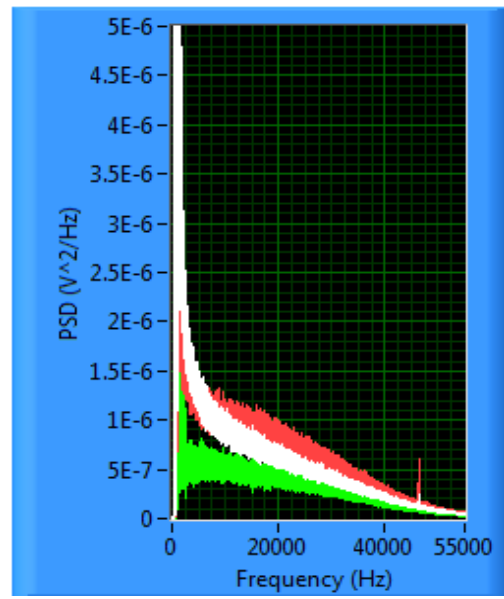

E: Load: $100 \Omega$ calibration resistor

Figure 4. Baseline measurement data at each test location. 


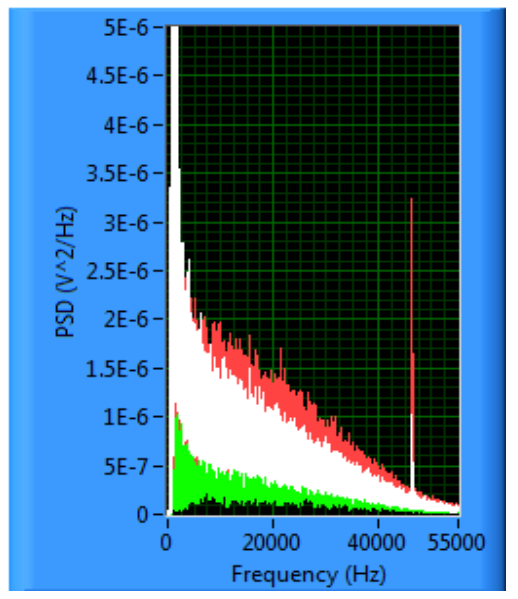

A: Load: $100 \Omega$ calibration resistor

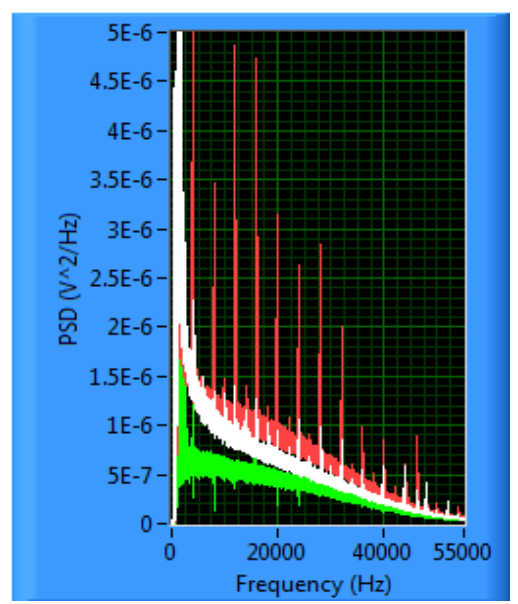

B: Load: (L4) Cable 2, RTD 2

Figure 5. Measurement data with all subsystems (except heaters) on at two locations.

Next, the heaters and two TACs were turned on. Measurement results, displayed in Figure 6, confirm a large amount of EMI corrupting G1, G2, and G12. However, the electronics did not saturate right away (Table 1). Note the baseline rises with the extra EMI, resulting in inaccurate reporting of temperature. This is a good test of the tolerance of the system to EMI.

After a few hours of operation, the operators shut down the loop. The loop generated an unknown noise that is concerning. All subsystems, TACs, and heaters are turned off. However, the temperature of the loop takes some time to cool to room temperature. The measurement results from both shutdown and cooldown are displayed in Figures 7 and 8.

The important points shown by the data are as follows.

1. Enough EMI will paralyze the system. As shown in Figure 6, it is possible to inject a sufficient amount of EMI to make the measurement unusable.

2. EMI will be averaged out only if it is not correlated between the two channels. The uncorrelated signals are removed during cross-correlation operations. If EMI is injected onto the RTD itself and is correlated in both channels, the correlated portion appears to be part of the desired signal. This makes shielding and isolated wells extremely important.

3. JNT system will survive real-world application environments. While the system did saturate eventually, it survived large amounts of EMI. The rejection method was not able to accurately compute temperature and therefore motivated development of a new method. The subtraction method is able to remove this EMI reliably, allowing for an accurate temperature measurement. Actually, the larger the EMI, the better the subtraction method is at removing it. 


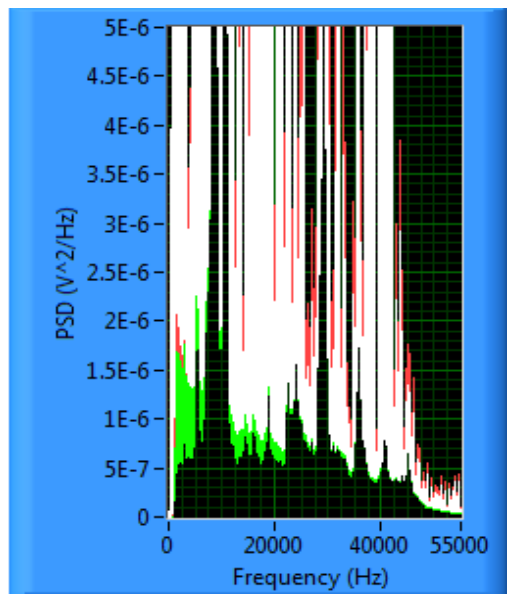

A: Load: (L1) Cable 4, RTD 3

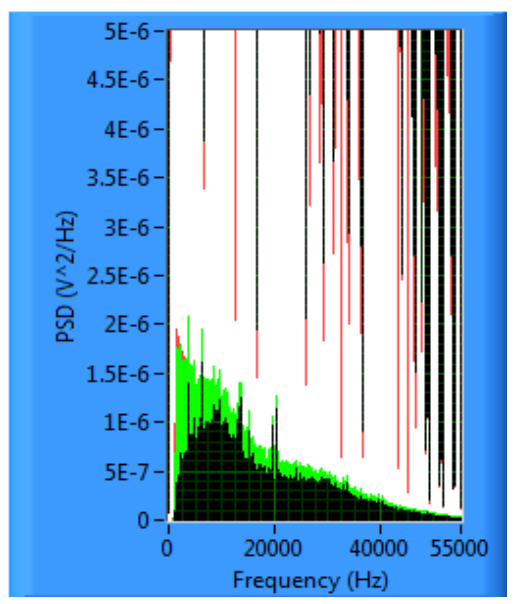

C: Load: (L3) Cable 6, RTD 4

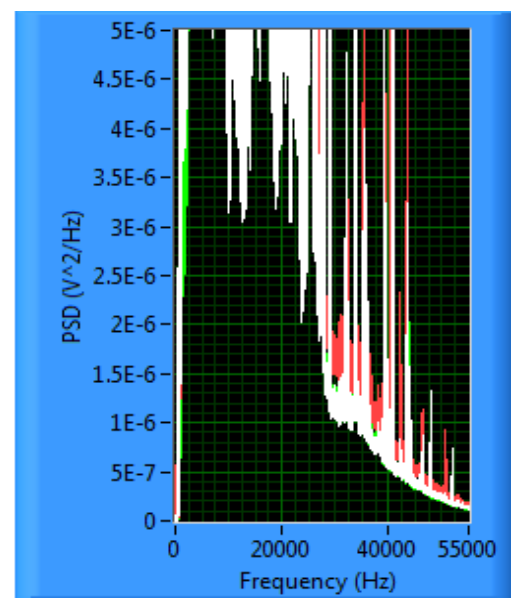

B: Load: (L2) Cable 1, RTD 1

\section{NO DATA Recorded At this Location}

D: Load: (L4) Cable 2, RTD 2

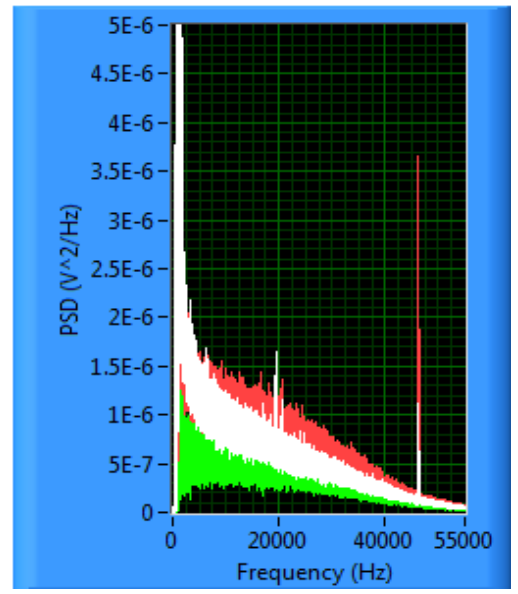

E: Load: $100 \Omega$ Calibration Resistor

Figure 6. Measurement data with all subsystems on, heaters on, TAC on at each location. 


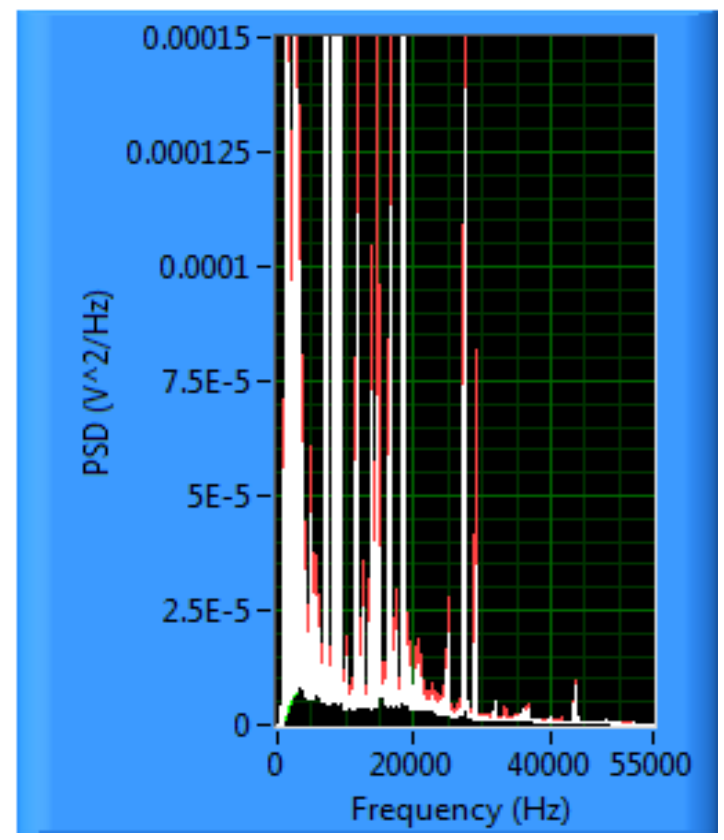

Load: (L2) Cable 1, RTD 1

Figure 7. Measurement data with all subsystems on, heaters on, TAC on; then system turned off during measurement.

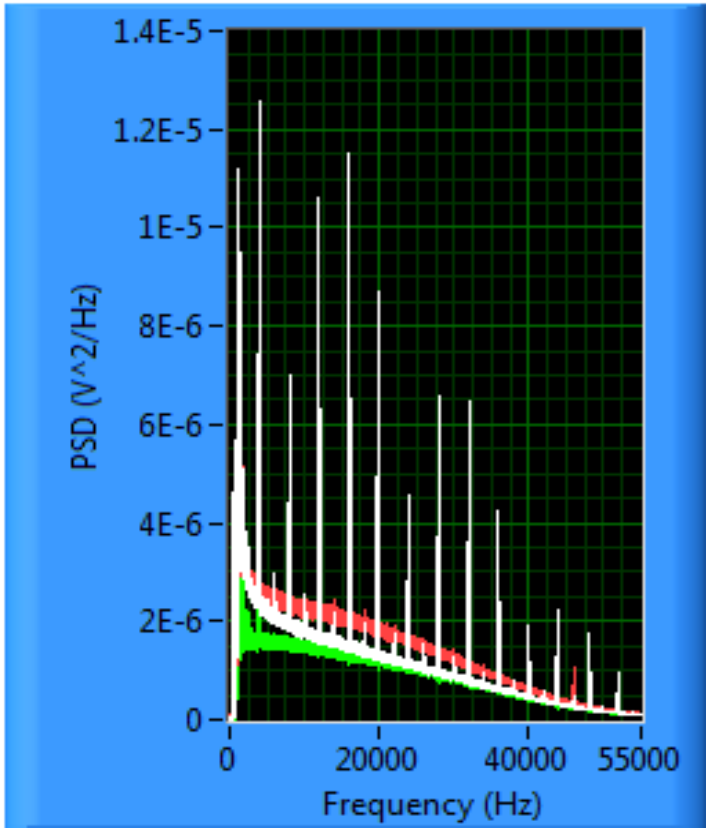

Load: (L2) Cable 1, RTD 1

Figure 8. Measurement data with all subsystems off during cooldown. 


\section{CONFIGURATION OF THE SYSTEM FOR SUBTRACTION}

As presented in the previous reports [1]-[5], the JNT system consists of several parts, shown in Figure 9. This system is identical to the original system with the addition of one channel. This report describes the additional subtraction system components. All other components are identical to previous designs [1]-[5].

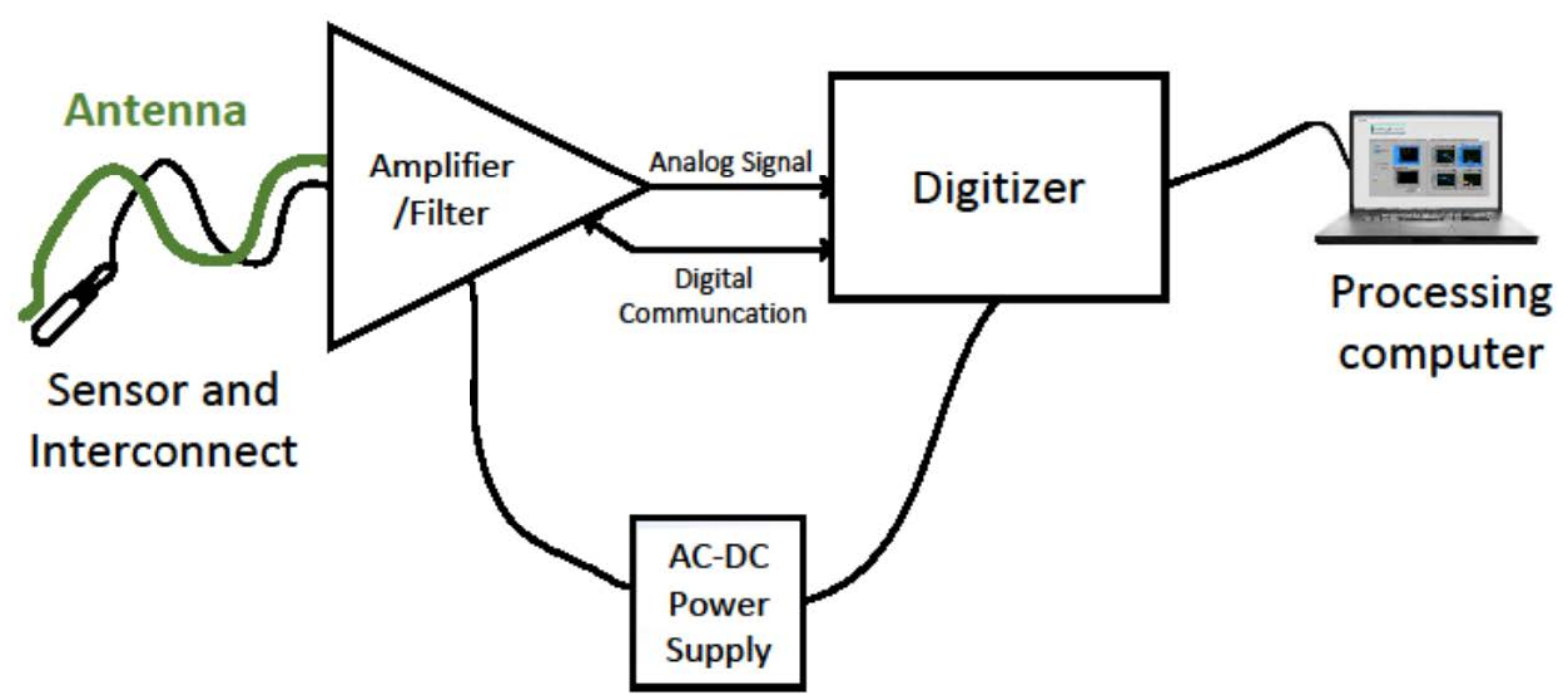

Figure 9. Johnson noise thermometry system block diagram.

\section{Antenna and Associated Electronics (Amplifier/Filter)}

1. Antenna. Several antenna configurations were tested, but ultimately a simple wire antenna that runs along the RTD cable was good enough for proof of concept. The antenna provides the environmental information needed to accurately remove EMI from the JNT voltage output signal.

2. Preamplifier. The preamplifier design consists of a low noise amplifier with the necessary gain to increase the signal to a point where the electronic noise of successive stages will not be a significant source of error.

The JNT signal of the RTD uses a differential measurement by two independent channels. The signal at each of the two channel outputs contains primarily the sensor noise plus a small amount of noise from the filters and the other amplifiers associated with the channel [1]. The software signal processing computes the cross-correlation noise between the two channels. This allows any uncorrelated and unwanted noise to average out over the measurement run time leaving only the signal of interest, the sensor noise.

3. Differential Amplifier/Gain. Differential amplifier and gain stage cancels most of the pickup noise.

4. Bandpass Filter/Gain. The bandpass filter design uses the sixth order Sallen-key filter topology with three stages to implement the high-pass and low-pass functions.

The antenna channel electronics are as identical to the two noise voltage channels as physically possible, allowing for comparable measurements [7]. 


\section{Signal Processing Technique}

The JNT measurement consists of output voltages from two amplifier/filter channels, each consisting of the sum of a correlated noise voltage and an uncorrelated amplifier/filter noise voltage. As the PSDs/CPSDs are time averaged, the power of the uncorrelated noise approaches zero. This same technique is in the rejection method. However, the subtraction method does not solely rely on crosscorrelation and averaging over time to remove the EMI noise. The antenna signal is acquired using the fifth high-speed channel and is subtracted from each amplifier/filter channel output voltage [7]. The signal processing steps to remove EMI with the subtraction method are displayed in Figures 10 and 11. The sample data from the amplifier/filter channels and the antenna form a block made of 16 sub-blocks. The order of operation is critical for the subtraction algorithm. To properly subtract EMI, the crossfrequency response of the antenna to the output of the JNT channels is established. First the antenna voltage is measured. Eq. (1) is representative of the antenna output voltage $\left(\mathrm{V}_{\mathrm{A}}\right)$. The CPSD between the antenna and amplifier/filter channel voltage outputs is given in Eqs. (2) and (3), and the PSD of VA is solved for in Eq. (4).

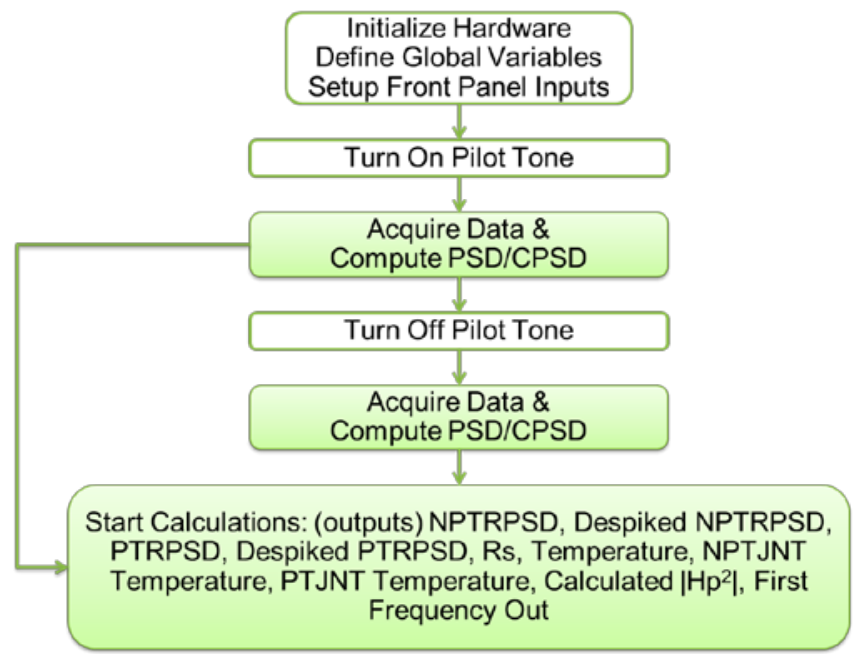

Figure 10. Flow chart of JNT signal processing [7].

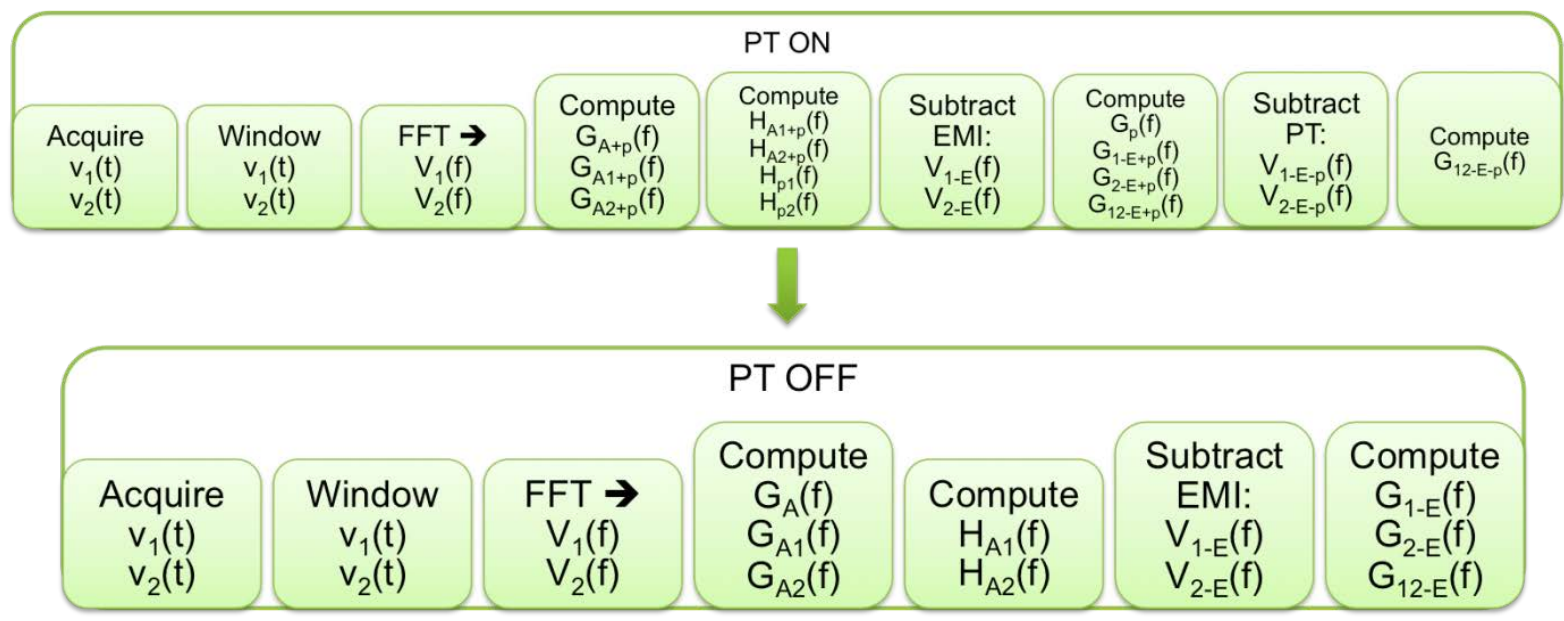

Figure 11. Block diagram of steps for subtraction method algorithm [7]. 


$$
\begin{gathered}
V_{A}(f)=\left[X_{E}(f) H_{E A}(f)+V_{a 3}(f)\right] H_{a 3}(f) \\
G_{A 1, E}(f)=\lim _{\Delta \rightarrow \infty} E\left(\frac{V_{A, \Delta}^{*}(f) V_{1 E, \Delta}(f)}{\Delta}\right)=G_{E}(f) H_{E A}^{*}(f) H_{a 3}^{*}(f) H_{E s}(f) H_{s}(f) H_{1}(f) \\
G_{A 2, E}(f)=\lim _{\Delta \rightarrow \infty} \mathrm{E}\left(\frac{V_{A, \Delta}^{*}(f) V_{2 E, \Delta}(f)}{\Delta}\right)=G_{E}(f) H_{E A}^{*}(f) H_{a 3}^{*}(f) H_{E s}(f) H_{s}(f) H_{2}(f) \\
G_{A}(f)=\lim _{\Delta \rightarrow \infty} \mathrm{E}\left(\frac{\left|V_{A, \Delta}(f)\right|^{2}}{\Delta}\right)=G_{E}(f)\left|H_{E A}(f) H_{a 3}(f)\right|^{2}+G_{a 3}(f)\left|H_{a 3}(f)\right|^{2}
\end{gathered}
$$

$\mathrm{G}_{\mathrm{A1}, \mathrm{E}}(\mathrm{f})$ is the CPSD between the antenna and channel 1 voltage outputs, $\mathrm{G}_{\mathrm{A1}, \mathrm{E}}(\mathrm{f})$ is the CPSD between the antenna and channel 2 voltage outputs, $\mathrm{G}_{\mathrm{E}}(\mathrm{f})$ is the PSD of the EMI, and $\mathrm{H}_{\mathrm{E}}(\mathrm{f})$ is the frequency response of the EMI. $\mathrm{H}_{\mathrm{EA}}(\mathrm{f})$ is the frequency response of the EMI-to-antenna voltage, $\mathrm{V}_{\mathrm{a} 3}(\mathrm{f})$ is the antenna's associated channel electronics noise, and $\mathrm{H}_{\mathrm{a} 3}(\mathrm{f})$ is the frequency response of the antenna channel electronics. Using the CPSD between the antenna and the channel outputs $\left[\mathrm{G}_{\mathrm{A} 1}(\mathrm{f}), \mathrm{G}_{\mathrm{A} 2}(\mathrm{f})\right]$ and the PSD of the antenna $\left[G_{A}(f)\right]$, the cross-frequency response of the antenna to the channel outputs is solved using Eq. (5). Equation 6 solves for the output voltages from each of the JNT channels with EMI subtracted, where $V_{1 E}(f)$ and $V_{2 E}(f)$ are the output voltages from two channels with EMI corruption, given in Eq. (7) [7].

$$
\begin{gathered}
H_{A 1}(f)=\frac{G_{A 1}(f)}{G_{A}(f)} \\
H_{A 2}(f)=\frac{G_{A 2}(f)}{G_{A}(f)} \\
V_{1-E}(f)=V_{1 E}(f)-H_{A 1}(f) V_{A}(f) \\
V_{2-E}(f)=V_{2 E}(f)-H_{A 2}(f) V_{A}(f) \\
V_{1 E}(f)=\frac{G_{A, 1 E}(f)}{G_{A}(f)} V_{A}(f) \\
V_{2 E}(f)=\frac{G_{A, 2 E}(f)}{G_{A}(f)} V_{A}(f)
\end{gathered}
$$

In Eqs. (5) and (6), $\mathrm{H}_{\mathrm{A1} 1}(\mathrm{f})$ and $\mathrm{H}_{\mathrm{A} 2}(\mathrm{f})$ are the frequency responses from the output voltage of the antenna electronics to the JNT channel output voltages. The EMI detected by the antenna and the EMI noise corrupting the channel output voltages are coherent, making this subtraction technique possible [6]. The better the EMI is detected by the antenna, the better the model of the EMI environment $\left[\mathrm{H}_{\mathrm{EA}}(\mathrm{f})\right]$ and 
therefore the better the subtraction method performs. Now that the voltage signals no longer have EMI corruption, the CPSD between the two signals is computed [Eq. (8)], similar to the rejection method [1][5].

$$
G_{12-E}(f)=\lim _{\Delta \rightarrow \infty} E\left(\frac{V_{1-E, \Delta}^{*}(f) V_{2-E, \Delta}(f)}{\Delta}\right)=\left[G_{R s}(f)+G_{R c}(f)\right]\left|H_{s}(f)\right|^{2} H_{1}(f) H_{2}(f)
$$

The final temperature calculation depends heavily on the CPSD between JNT channels 1 and 2 being accurate and independent of the EMI environment:

$$
T_{s}=\left[\frac{G_{12}(f)}{H_{12}(f)}-G_{R c}(f)\right] \times\left[\frac{1}{2 k R_{s}}\right],
$$

where $\mathrm{H}_{12}(\mathrm{f})$ is the cross-power frequency response from the sensor to the outputs of channels 1 and 2 , $\mathrm{G}_{\mathrm{Rc}}(\mathrm{f})$ is the PSD of the cable resistance, $k$ is Boltzmann's constant, and $\mathrm{R}_{\mathrm{s}}$ is the sensor resistance. Using this method has proven better than the rejection method because more EMI sources are detected and removed.

\section{VALIDATION OF SUBTRACTION ALGORITHM}

The subtraction method was validated through testing at ORNL before it was taken to other facilities. First the system was tested under the cleanest environment with minimal EMI (referred to as an ambient environment). This was used as a baseline test for the system.

The CPSD between the two JNT channels, displayed in Figure 12, is from testing with the system in an ambient environment. These results reveal EMI noise sources at $60 \mathrm{~Hz}$, at $27 \mathrm{kHz}$ from the light ballast, at $44 \mathrm{kHz}$ from the internal signal generator, and at $63 \mathrm{kHz}$ from an unidentified noise source from inside the JNT front end board. The results displayed in Figure 12A show the subtraction method from a single test run. The results displayed in Figure 12B show the subtraction method from multiple test runs, including the results displayed in Figure 12A. The subtraction method is accurately and repetitively removing the EMI noise sources across multiple measurement runs.

The system is then subjected to environments with generated EMI; Table 2 lists these environments. All contributing noise sources from the ambient environment will be present in the testing of these environments.

The first EMI environment tested is a single sine wave with a frequency of $20 \mathrm{kHz}$ ( $0.05 \mathrm{msec}$ period). To generate these noise environments a large coil antenna is driven by a bipolar power amplifier. An Agilent 3351A signal generator controls the signal input to the amplifier (Figure 13). 


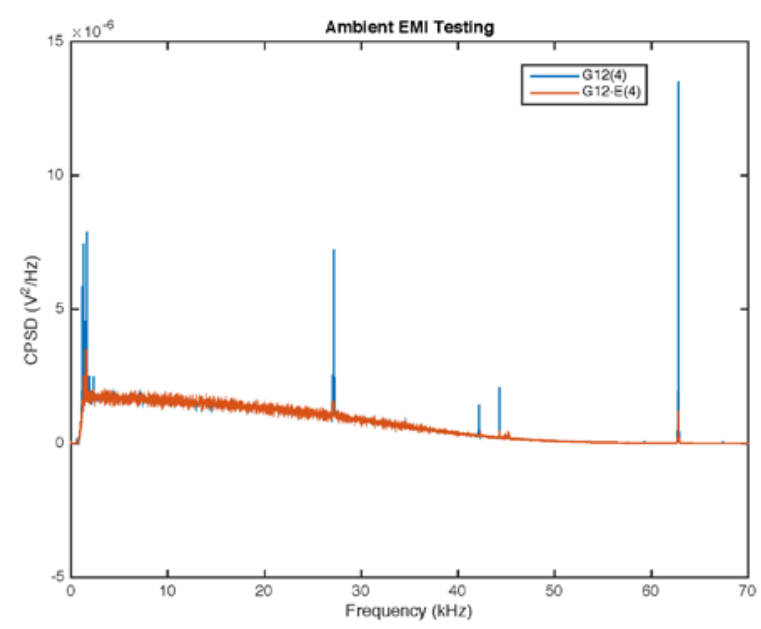

A: Single measurement results from 3-hour measurement

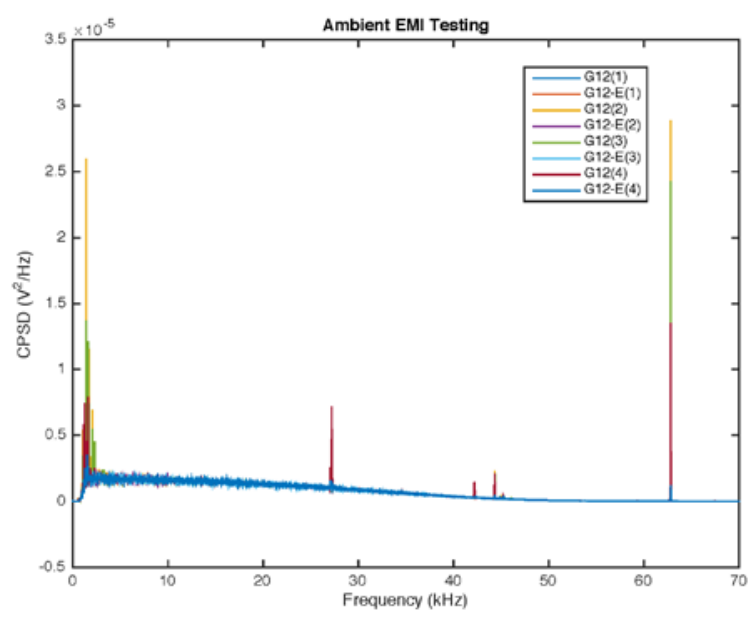

B: Multiple measurement results from 3-hour measurement

Figure 12. Measurement results from ambient EMI environment.

Table 2. EMI environments generated for validation of subtraction method

\begin{tabular}{l|l}
\hline EMI environment 1 (EE1) & Single Sine $(20 \mathrm{kHz})$ EMI—tested in ice bath \\
EMI environment 2 (EE2) & Broadband EMI—tested in ice bath \\
EMI environment 3 (EE3) & Sandia EMI—tested in ice bath \\
\hline
\end{tabular}

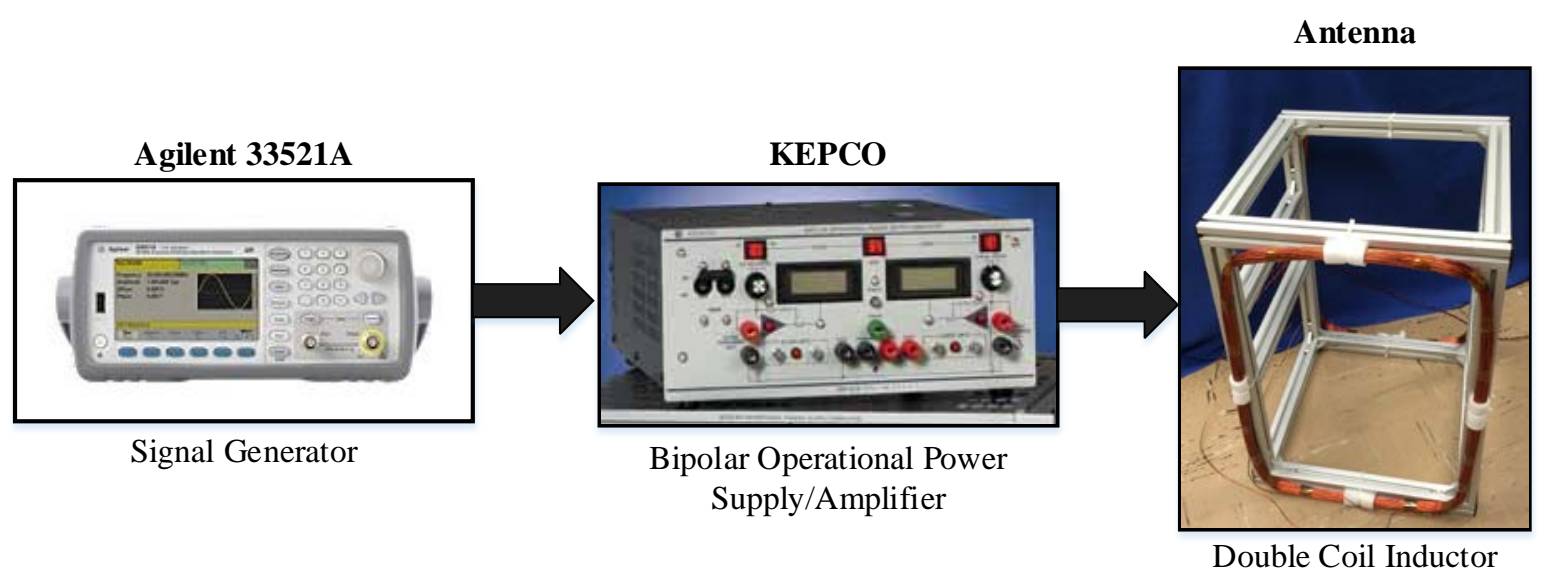

Figure 13. EMI generation system [7].

Results from EE1 (EMI environment 1) are displayed in Figure 14. Note the large spike at $20 \mathrm{kHz}$. The subtraction method removes this spike easily as shown in Figure 14A. The EMI is large and easily detected by the antenna, and therefore the frequency response of the antenna is very representative of the EMI environment. Figure 14B shows that the subtraction of this spike is repeatable across four different experimental measurements. 


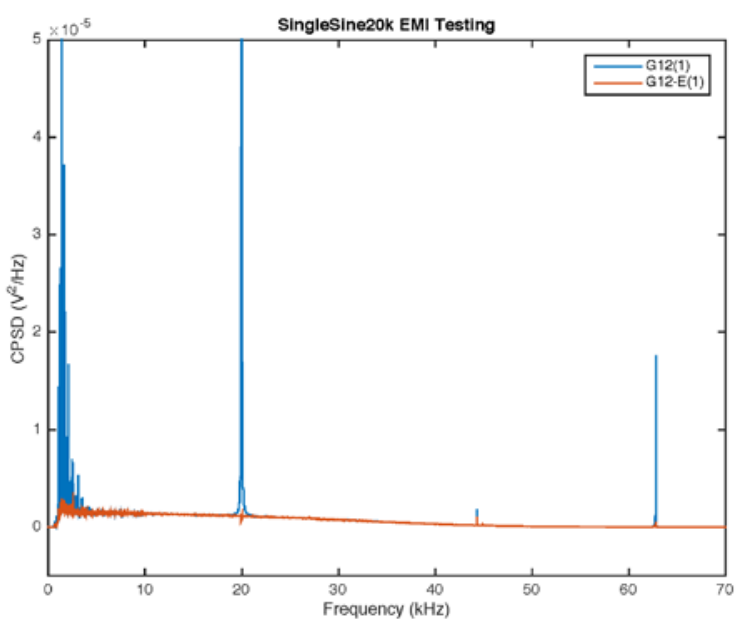

A: Single measurement results from 3-hour measurement

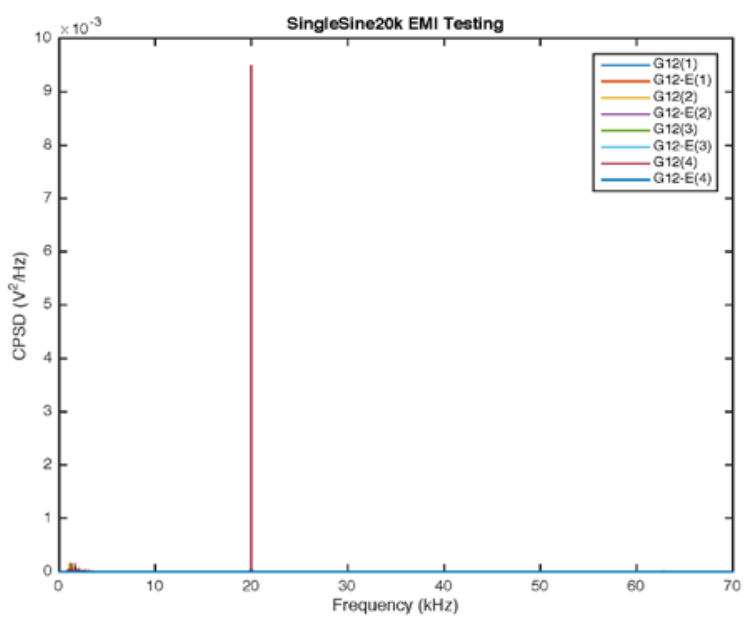

B: Multiple measurement results from 3-hour measurement

Figure 14. Measurement results from EMI environment 1 [7].

The next EMI environment is a broadband EMI, EE2. This experiment is important because the rejection method is not able to reject broadband EMI in its current configuration. The broadband EMI is difficult to reject but easy to subtract due to the frequency response of the EMI. A good antenna can detect broadband EMI, where the rejection method depends on well-defined spikes. Note the baseline data appear fuzzier due to the broadband EMI in Figure 15. The temperature computations are also accurate across multiple runs with this EMI environment.

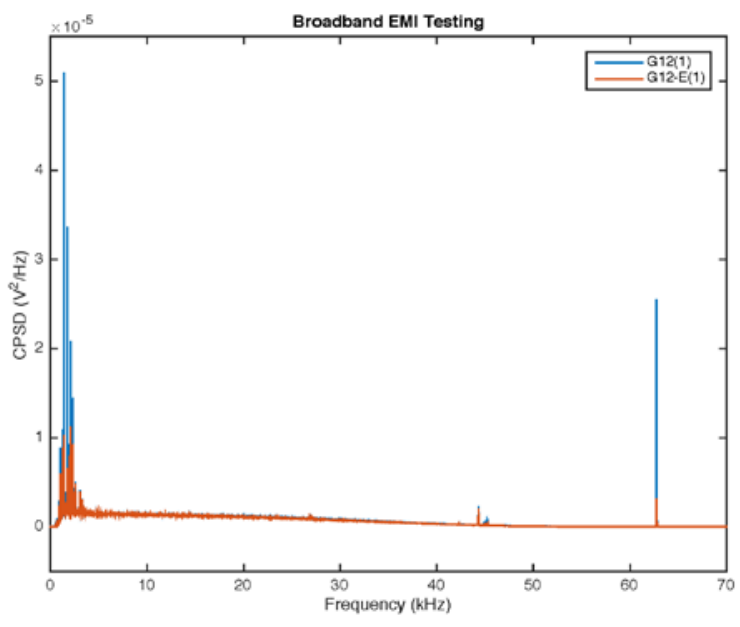

A: Single measurement results from 3-hour measurement

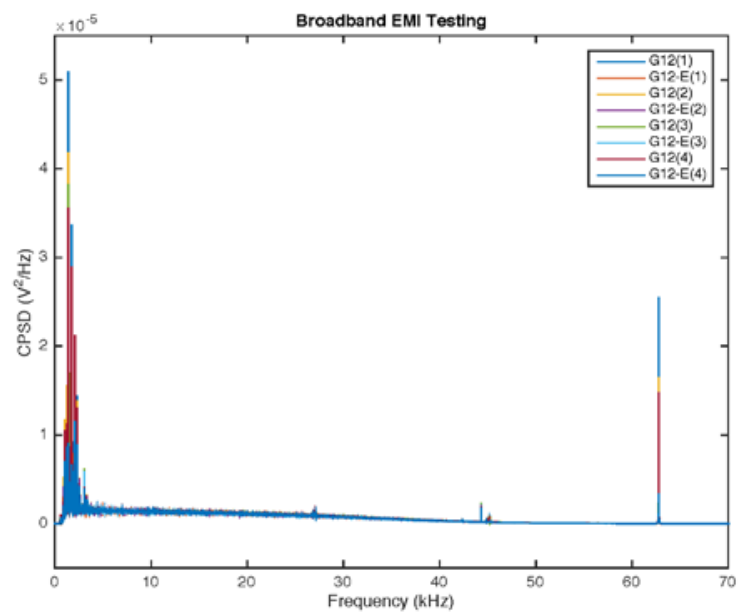

B: Multiple measurement results from 3-hour measurement

Figure 15. Measurement results from EMI environment 2 [7]. 
The last generated EMI environment (EE3) reflects the measured EMI from testing at Sandia (Figure 16). A $2 \mathrm{kHz}$ square wave is generated to reflect the measured results displayed in Figure 5 at location 4 and Figure 8 at location 2. The rejection method was able to remove some of this EMI over a long run time, whereas the subtraction method was able to detect the unwanted EMI noise and remove it quickly.

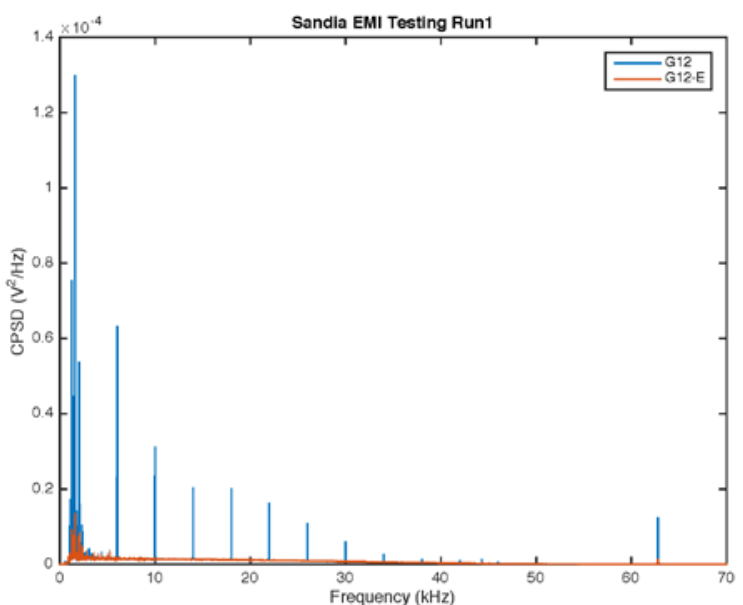

A: Single measurement results from 3-hour measurement

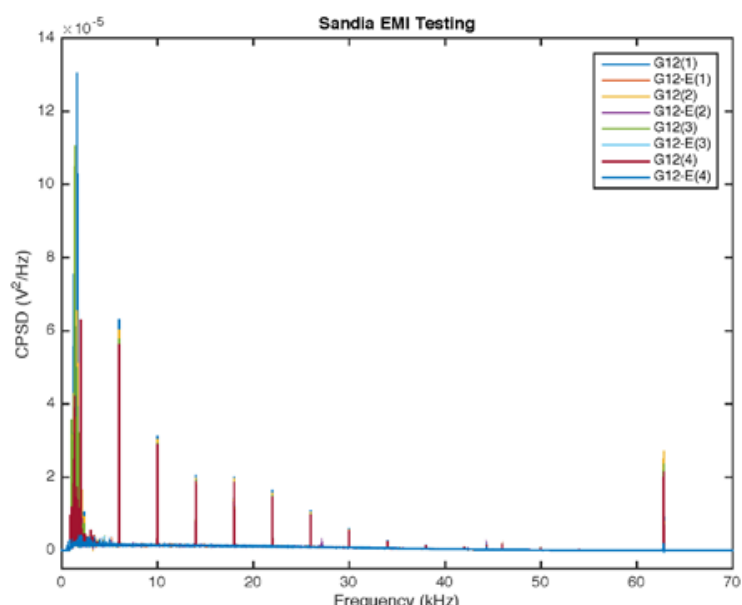

B: Multiple measurement results from 3-hour measurement

Figure 16. Measurement results from EMI environment 3 [7].

From these environmental experiments, it can be concluded that the subtraction method is superior to the rejection method at removing EMI without biasing the temperature measurement and baseline data. The subtraction method is able to model the EMI environment using an antenna and amplifier/filter electronics and then subtract the EMI from the windowed frequency domain data. This method does depend on a good antenna and some time to accurately generate the cross-frequency response. However, the amount of time is much less than that for the rejection method.

Another concern is whether the temperature computation tracks as the temperature changes. Table 3 outlines a wide range of temperature experiments. To heat the RTDs to the desired elevated temperatures a tube furnace was used (Figure 17).

Table 3. Temperatures under test

\begin{tabular}{l|l}
\hline Temperature case 1 & Ice bath $\left(0^{\circ} \mathrm{C}=273 \mathrm{~K}\right)$ \\
Temperature case 2 & $100^{\circ} \mathrm{C}=373.15 \mathrm{~K}$ \\
Temperature case 3 & $150^{\circ} \mathrm{C}=423.15 \mathrm{~K}$ \\
Temperature case 4 & $200^{\circ} \mathrm{C}=473.15 \mathrm{~K}$ \\
Temperature case 5 & $250^{\circ} \mathrm{C}=523.15 \mathrm{~K}$ \\
\hline
\end{tabular}




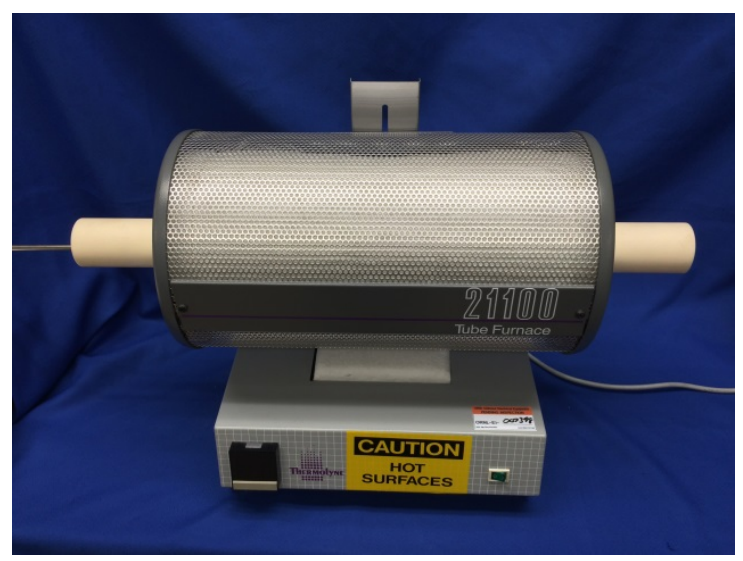

Figure 17. Tube furnace used in temperature testing.

In the first experiment, the RTD was placed in an ice bath. This test is a good baseline for temperature experiments because the only EMI present is from ambient environmental noise sources (Figure 18). The results from this experiment are similar to those shown in Figure 12. The only contributing noise sources are from $60 \mathrm{~Hz}, 27 \mathrm{kHz}$ (light ballast), $44 \mathrm{kHz}$ (internal signal generator), and $63 \mathrm{kHz}$ (unknown internal oscillation).

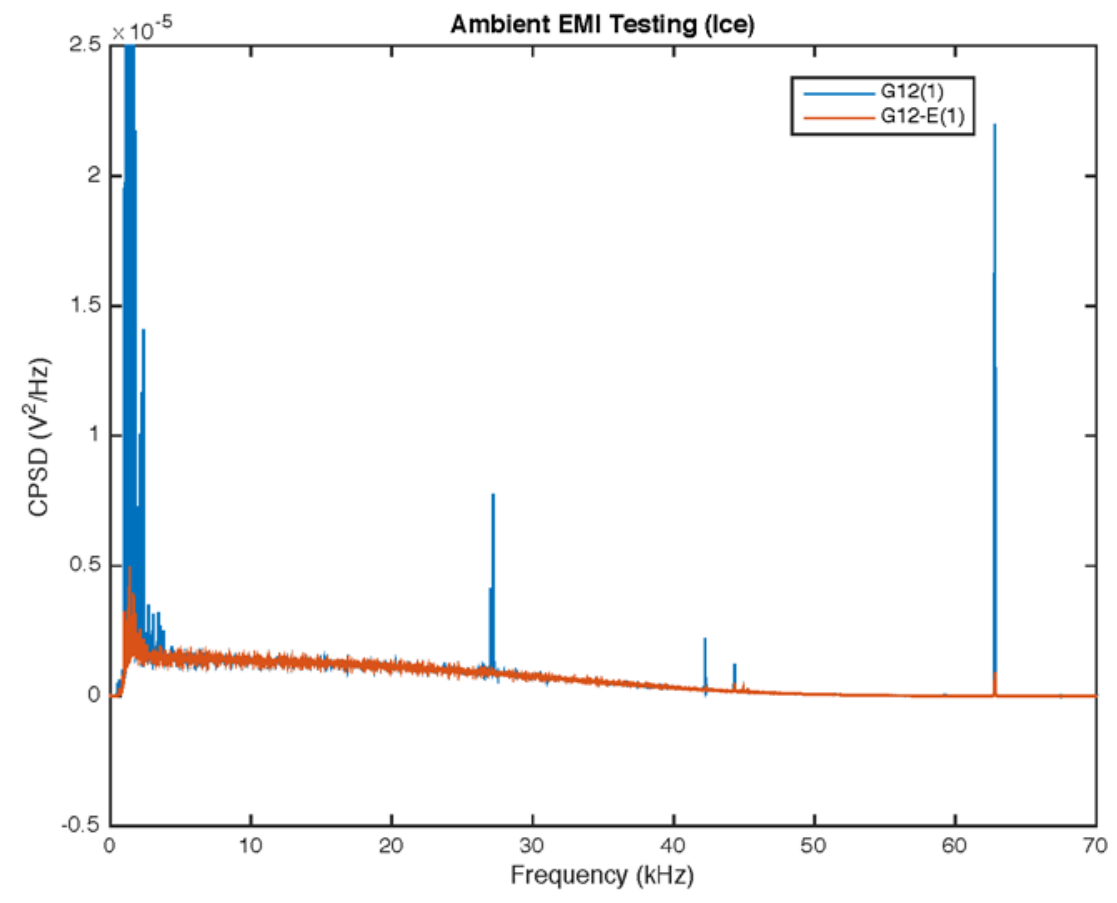

Figure 18. Measurement results for temperature case 1 [7].

Next, the RTD was placed inside the tube furnace, and the temperature of the furnace was set to $100^{\circ} \mathrm{C}$ (Figure 19). The measured temperatures from this experiment are given in Table 4. The furnace contributes some unwanted EMI noise due to the "burp" power function of the furnace. Added EMI from the furnace contributes EMI spikes at $13 \mathrm{kHz}, 35 \mathrm{kHz}, 40 \mathrm{kHz}$, and $58 \mathrm{kHz}$. Placing an antenna inside the furnace does allow for this noise to be accounted for. For this reason, a special high temperature antenna was designed, allowing for field measurements inside the furnace. All of the measurements inside the furnace had about the same noise spectrum. 


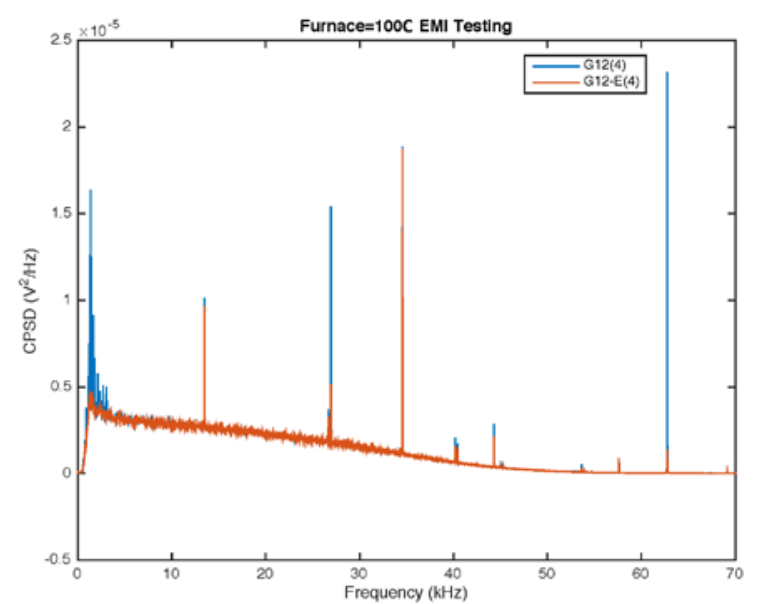

A: Single measurement results from 3-hour measurement

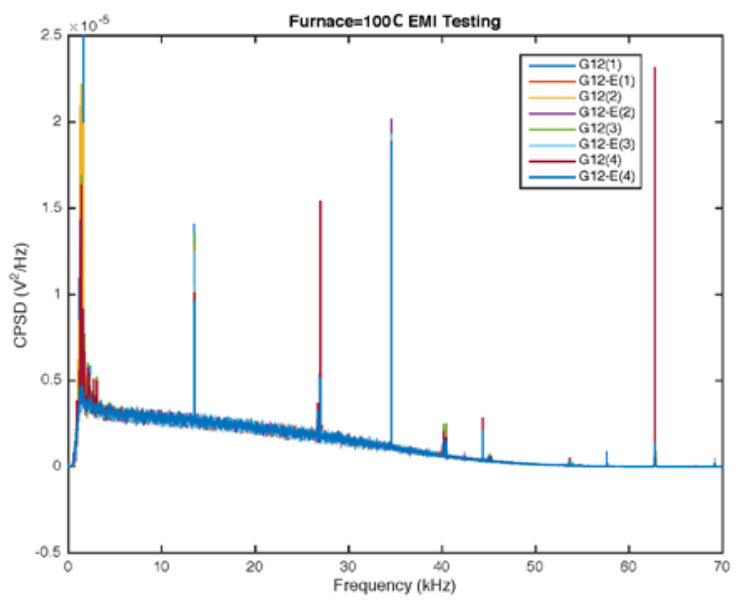

B: Multiple measurement results from 3-hour measurement

Figure 19. Measurement results from temperature case 2 [7].

Table 4. Temperature results from each temperature case [7]

\begin{tabular}{ll}
\hline \multicolumn{1}{c}{ Case } & \multicolumn{1}{c}{ Measured Temperature } \\
\hline & Test 1: $112.7^{\circ} \mathrm{C}$ \\
Temperature case 2 & Test 2: $113.74^{\circ} \mathrm{C}$ \\
$\left(114.15^{\circ} \mathrm{C}\right)$ & Test 3: $114.00^{\circ} \mathrm{C}$ \\
& Test 4: $118.05^{\circ} \mathrm{C}$ \\
& Test 1: $168.41^{\circ} \mathrm{C}$ \\
Temperature case 3 & Test 2: $168.57^{\circ} \mathrm{C}$ \\
$\left(\mathbf{1 6 8 . 1 5}^{\circ} \mathrm{C}\right)$ & Test 3: $167.2^{\circ} \mathrm{C}$ \\
& Test $4: 167.83^{\circ} \mathrm{C}$ \\
& Test 1: $221.36^{\circ} \mathrm{C}$ \\
Temperature case 4 & Test 2: $222.77^{\circ} \mathrm{C}$ \\
$\left(222.15^{\circ} \mathrm{C}\right)$ & Test 3: $222.87^{\circ} \mathrm{C}$ \\
& Test 4: $222.10^{\circ} \mathrm{C}$ \\
& Test $1: 275.8^{\circ} \mathrm{C}$ \\
Temperature case 5 & Test 2: $276.12^{\circ} \mathrm{C}$ \\
$\left(275.15^{\circ} \mathrm{C}\right)$ & Test 3: $275.69^{\circ} \mathrm{C}$ \\
& Test 4: $275.09^{\circ} \mathrm{C}$ \\
\hline
\end{tabular}

The furnace temperature was then increased to $150^{\circ} \mathrm{C}$ for temperature case 3 (Figure 20). Note the EMI noise contribution similarities between case 2 and case 3 . The temperature results from both of these experiments are given in Table 4. 


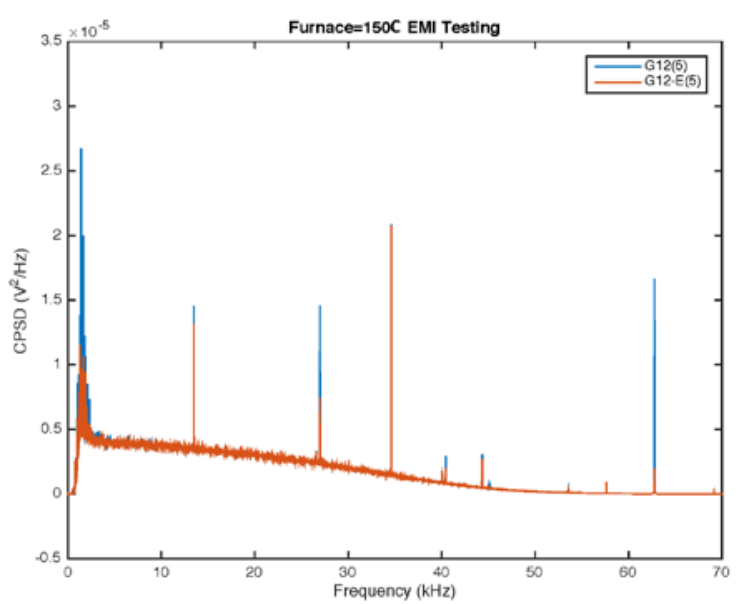

A: Single measurement results from 3-hour measurement

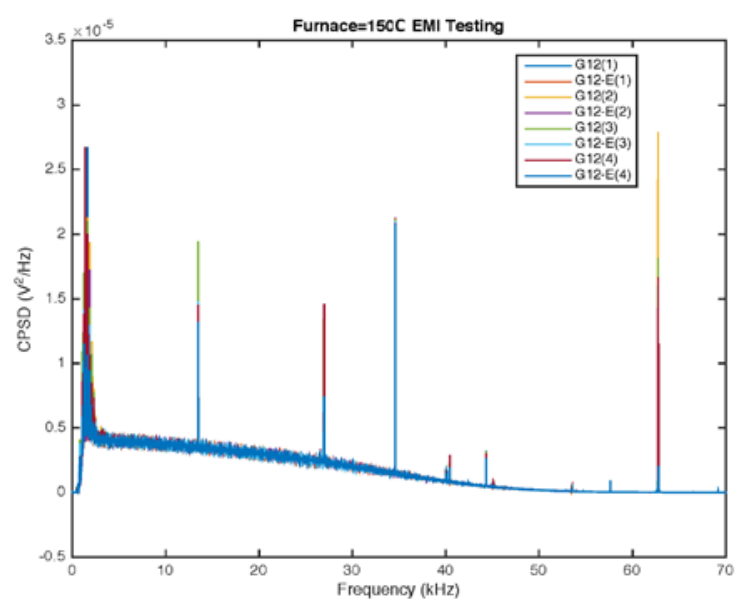

B: Multiple measurement results from 3-hour measurement

Figure 20. Measurement results from temperature case 3 [7].

Next, the furnace temperature was increased to $200^{\circ} \mathrm{C}$, and multiple experiments at temperature case 4 were performed (Figure 21). The temperature results from these experiments are given in Table 4.

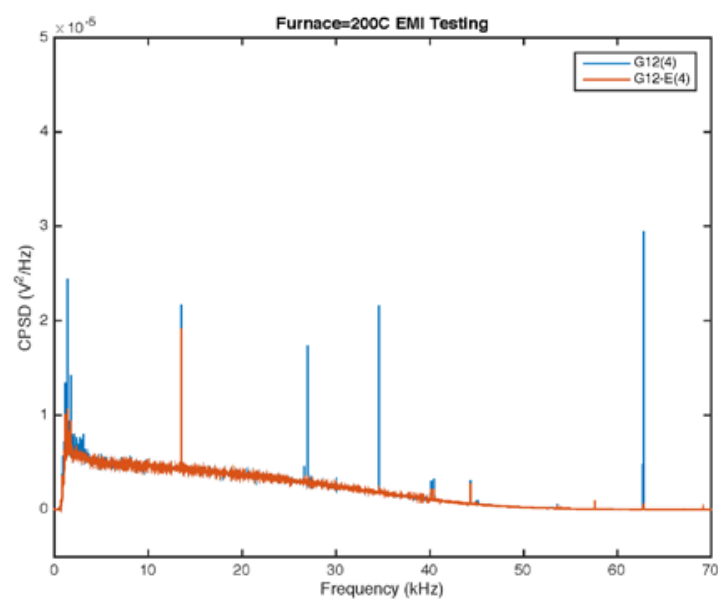

A: Single measurement results from 3-hour measurement

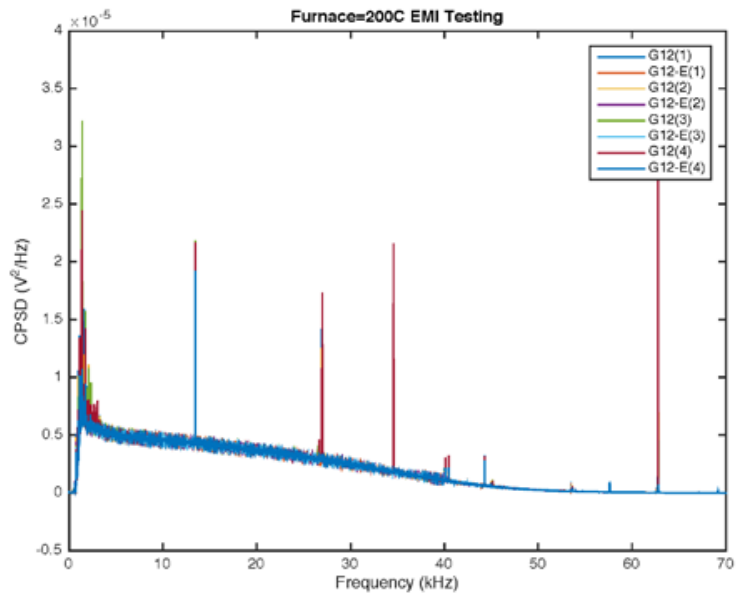

B: Multiple measurement results from 3-hour measurement

Figure 21. Measurement results from temperature case 4 [7].

Finally, the furnace temperature was elevated to $250^{\circ} \mathrm{C}$, and experiments were performed (Figure 22). The baseline data for this case, as well as all the other temperature cases where the furnace was used, were the same. The shape of the baseline data reflects the transfer function of the electronics, and the magnitude is the CPSD between JNT channels 1 and 2. 


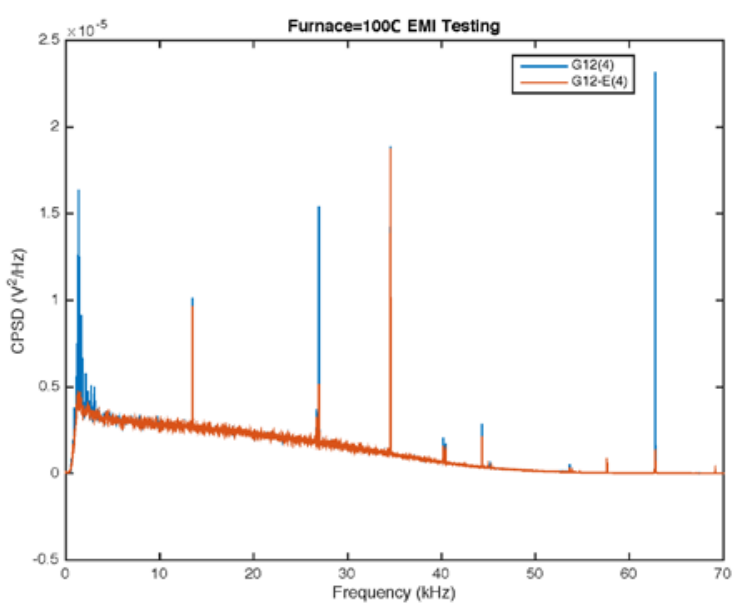

A: Single measurement results from 3-hour measurement

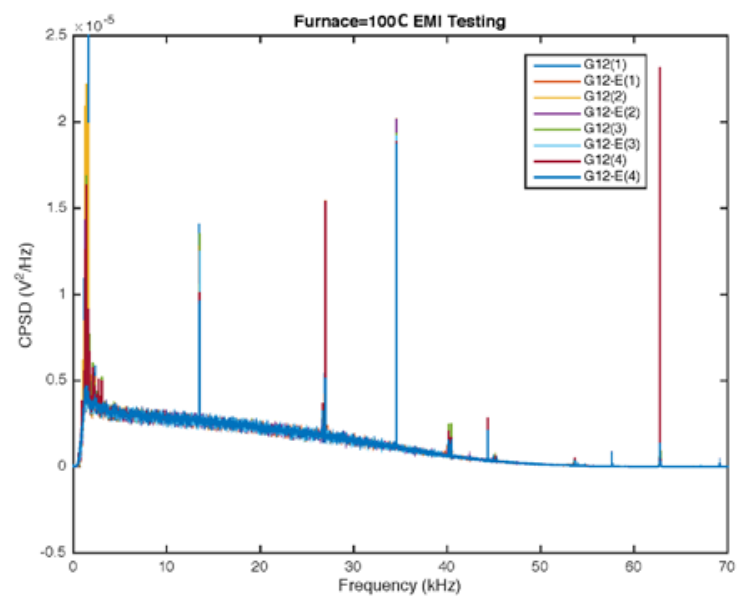

B: Multiple measurement results from 3-hour measurement

Figure 22. Measurement results from temperature case 2 [7].

The results from the temperature testing demonstrate that even with elevated temperature cases the subtraction method is able to properly remove EMI and compute temperatures accurately and repeatedly.

\section{CONCLUSION}

The success of the rejection method depends largely on the environment into which it is deployed; therefore, the subtraction method was developed. This method actually works better with large amounts of EMI. Testing at Sandia reaffirmed the abilities of the rejection method but also displayed holes in the method. Testing results from the Sandia measurements were remodeled for proof of concept of the subtraction method. Elevated temperature experiments also displayed the superiority of the subtraction method to the rejection method.

\section{REFERENCES}

[1] N. Dianne Bull Ezell, Charles L. Britton, Jr., and Michael Roberts, Report of the EMI Testing of Johnson Noise Thermometry System, ORNL/TM-2014/237, SMR/ICHMI/ORNL/TR-2013/01, June 2014.

[2] Charles L. Britton, Jr., Michael Roberts, Nora D. Bull, Lou Qualls, and David E. Holcomb, Johnson Noise Thermometry Requirements, ORNL/TM-2013/2, SMR/ICHMI/ORNL/TR-2013/01, January 2013.

[3] Charles L. Britton, Jr., Michael Roberts, Nora D. Bull, , David E. Holcomb, and Richard T. Wood, Johnson Noise Thermometry for Advanced Small Modular Reactors, ORNL/TM-2012/346, SMR/ICHMI/ORNL/TR-2012/01, September 2012.

[4] Charles L. Britton, Jr., Nora D. Bull, Michael Roberts, Amplifiers Module Prototype for the Johnson Noise Thermometry System, ORNL/TM-2013/192, SMR/ICHMI/ORNL/TR-2012/03, May 2013. 
[5] Charles L. Britton, Jr., N. Dianne Bull Ezell, Michael Roberts, Johnson Noise Thermometry DataAcquisition Backend, ORNL/TM-2013/499, SMR/ICHMI/ORNL/TR-2013/06, October 2013.

[6] http://energy.sandia.gov/energy/nuclear-energy/advanced-nuclear-energy/nuclear-technology-usersfacility-ntuf/.

[7] N. Dianne Bull Ezell, “An Innovative Approach to Johnson Noise Thermometry by Means of Spectral Estimation.” PhD diss., University of Tennessee, 2016. 